\title{
Click Chemistry in Materials Science
}

\author{
Weixian Xi, Timothy F. Scott, Christopher J. Kloxin, and Christopher N. Bowman*
}

Despite originating only a little more than a decade ago, click chemistry has become one of the most powerful paradigms in materials science, synthesis, and modification. By developing and implementing simple, robust chemistries that do not require difficult separations or harsh conditions, the ability to form, modify, and control the structure of materials on various length scales has become more broadly available to those in the materials science community. As such, click chemistry has seen broad implementation in polymer functionalization, surface modification, block copolymer and dendrimer synthesis, biomaterials fabrication, biofunctionalization, and in many other areas of materials science. Here, the basic reactions, approaches, and applications of click chemistry in materials science are highlighted, and a brief look is taken into the future enabling developments in this field.

\section{Introduction}

The marriage between click chemistry and materials science is one that had been destined to occur for many years. Perhaps more than in any other field, the goal of materials scientists, engineers, and manufacturers has been to achieve performance and a set of desired characteristics in the final material and/or device in as simple and effective a manner as possible. These performance targets include specifications on mechanical and physical behavior, such as toughness, modulus, glass transition temperature, refractive index, and clarity, as well as chemical attributes such as solvent (in)compatibility, surface energy, chemical functionality, and biocompatibility. Process considerations such as the raw materials, process safety, solvent, and environmental considerations are also of great importance. This focus on material properties and performance aligns well

\section{W. Xi, Dr. C. N. Bowman}

Department of Chemical and Biological Engineering

Materials Science and Engineering Program

University of Colorado

Boulder, Colorado 80309-0596, USA

E-mail: christopher.bowman@colorado.edu

Dr. T. F. Scott

Department of Chemical Engineering

University of Michigan

Ann Arbor, Michigan 48109-2136, USA

Dr. C. J. Kloxin

Department of Materials Science \& Engineering

150 Academy Street, Newark, Delaware 19716, USA

Dr. C. J. Kloxin

Department of Chemical \& Biomolecular Engineering University of Delaware

150 Academy Street, Newark, Delaware 19716, USA with the goals espoused by Sharpless and coworkers when they first introduced the "click" chemistry paradigm, wherein they argued that the focus of chemical process selection should be directed towards the identification, optimization, and simplification of an overall process. ${ }^{[1]}$ Thus, this process identification includes the selection of initial target molecules, starting materials, and the reactions used to synthesize them, ultimately leading to the straightforward generation of a compound with the desired properties via a simple, robust process.

The click chemistry philosophy was first introduced in part as a response to the intense and ongoing research focus on the development of methods for the synthesis of ever more complex natural products. ${ }^{[1]}$ This chemistry development has historically focused on the creation of stereospecific carbon-carbon bonds and typically requires an array of protecting group strategies, sequential reactions, and various purification techniques. One main criticism advanced by Sharpless and co-workers is that conventional approaches to the natural products synthesis are too heavily invested in structure and that a great deal of discovery can be done by utilizing only 'a few good reactions'. "These reactions, now denoted as 'click' reactions, encompass a utilitarian framework and are defined by their common attributes of being modular and orthogonal as well as proceeding under simple and mild reaction conditions while affording high yields of a single product with facile purification." As a consequence of the simplicity of click reactions, synthesis and chemical modification has become far more accessible to a wide community of researchers, particularly in the materials arena, who previously would not have considered venturing into organic chemistry. In fact, a recent highlight identified specific criteria for the categorization of reactions in polymer chemistry as click reactions that can serve as a guidepost in this area. ${ }^{[2]}$ Moreover, owing to the modular nature of the chemistry, it provides a simple framework for the rapid discovery of new functional materials.

The original click chemistry paper, presented by Kolb, Finn, and Sharpless, described a handful of "spring-loaded" reactions that meet the click-chemistry standard. These chemistries often involve heteroatom linkages (i.e., $\mathrm{C}-\mathrm{X}-\mathrm{C}$ ) and a significant thermodynamic driving force (typically $>20 \mathrm{kcal} / \mathrm{mol}$ ). While identifying several reactions that meet these criteria, most importantly, their paper provides a framework through which to identify click reactions and processes. For example, the celebrated copper-catalyzed azide-alkyne click reaction was obviously not included, as it had not been published until a year later in 2002..$^{[3,4]}$ Furthermore, although the radical-mediated 
thiol-ene reaction was also not included in the seminal click paper, under a wide range of conditions, it clearly exhibits all of the characteristics described by Sharpless and co-workers and has become ubiquitous in materials science applications.

The thiol-ene reaction also demonstrates one of the limitations of the click reaction paradigm as well. In fact, each of the reactions described in the remainder of this manuscript has been oft-cited as a click reaction, and each exhibits the click characteristics over a wide range of conditions and for a wide range of reaction/coupling types ranging from polymer conjugation to surface modification to polymerization to polymer functionalization and many others. That said, prudent selection of reaction conditions, catalyst levels and reactive substrates remains critical even with these broadly useful, robust, nearly ideal reactions. For example, in implementing the thiol-ene reaction, one must be careful to eliminate other substratecatalyst combinations that cause non-orthogonality, ${ }^{[5,6]}$ and one must also assure that the initiator and oxygen concentrations are below the level of tolerable side reactions. ${ }^{[7,8]}$

In subsequent sections, we will highlight common click reactions and strategies for incorporating click targets into materials. We will also demonstrate how just a handful of efficient reactions enables a paradigm shift in materials development. As will be apparent throughout this article, the click philosophy wholly coincides with the goal of creating customizable material structures, behavior and performance. This manuscript is meant to highlight the reaction characteristics that make a reaction appropriate as a click reaction, identify the most useful reactions for materials science that have been characterized as click reactions, and discuss representative examples of the implementation of these reactions in various materials science applications. With more than 1500 papers published in click chemistry that are relevant to materials or polymer science just between 2010 and 2012, it is impossible to review each paper in the field thoroughly though we hope to highlight the most common reactions, their mechanisms, and representative examples of their implementation in materials science.

\section{Click Chemistries}

In the next sections, we review several of the reactions most frequently identified and implemented as click reactions in materials science, addressing briefly their history, mechanism, and relative advantages and disadvantages. Azide-alkyne cycloaddition, thiol-click reaction, Diels-Alder reaction, nitrile oxide cycloaddition, tetrazole cycloaddition, and oxime formation (see Figure 1) are selected here as representatives because of their fast reaction kinetics and wide utility in applications. While these are but a fraction of the total number of reactions that fall within the click philosophy, each of our selected reactions has recently been implemented and is particularly versatile in the context of material synthesis and functionalization. ${ }^{[2]}$

\subsection{Azide-Alkyne Cycloaddition}

Since its inception in $2001,^{[1]}$ a diverse array of click reaction mechanisms has been employed in materials science. Sharpless et al. ${ }^{[1]}$ held the $[3+2]$ cycloaddition between an

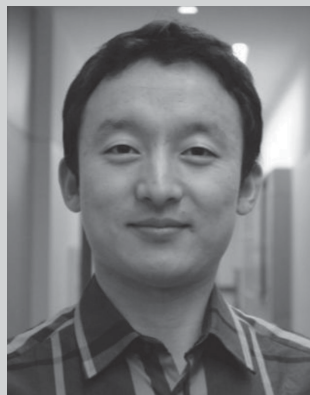

Weixian $\mathrm{Xi}$ received his B.S. in Chemical Biology from Tsinghua University (China) in 2010. He is a PhD candidate working in the laboratory of Dr. Bowman at University of Colorado Boulder. His research is focused on sequence-controlled polymer synthesis, and the development of novel catalysts for "click" reactions.

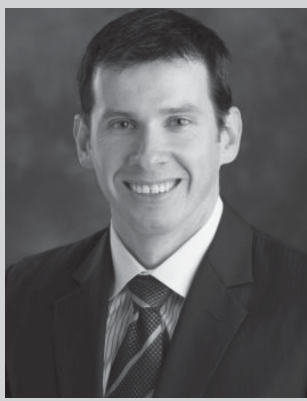

Timothy F. Scott is an Assistant Professor in the Department of Chemical Engineering and the Macromolecular Science and Engineering Graduate Program at the University of Michigan. His research within the Scott group is focused on the reaction kinetics and thermodynamics of dynamic covalent chemistries, and on exploiting the attributes of radicals for unique polymer fabrication and manipulation strategies to yield materials for biomedical devices, membrane separators and energy capture and storage media.

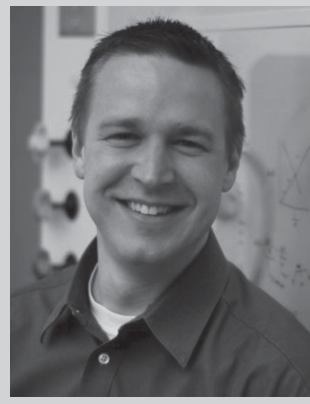

Christopher Kloxin is an Assistant Professor in the Departments of Materials Science and Engineering and Chemical and Biomolecular Engineering at the University of Delaware. His research efforts have focused on new photo-initiated click reaction schemes as well as the creation and characterization of covalent adaptable networks. In 2011, he began at the University of Delaware, where his research group utilizes a combination of click and reversible chemical motifs for the design and synthesis of nature-inspired polymeric materials.



Christopher Bowman is a Distinguished Professor and the James and Catherine Patten Chair in Chemical and Biological Engineering as well as the Director of the Materials Science and Engineering Program at the University of Colorado at Boulder. His research is focussed on polymeric materials, particularly polymer networks derived from photopolymerization reactions. He seeks to integrate molecular design, monomer and polymer synthesis, and polymer and polymerization analysis to create smart, responsive polymeric materials that achieve unique behavior and capabilities.

azide and an alkyne to afford a 1,2,3-triazole ${ }^{[9]}$ to be the archetypal exemplar of the click chemistry philosophy. However, this reaction yields both the 1,4- and 1,5-regioisomer addition 

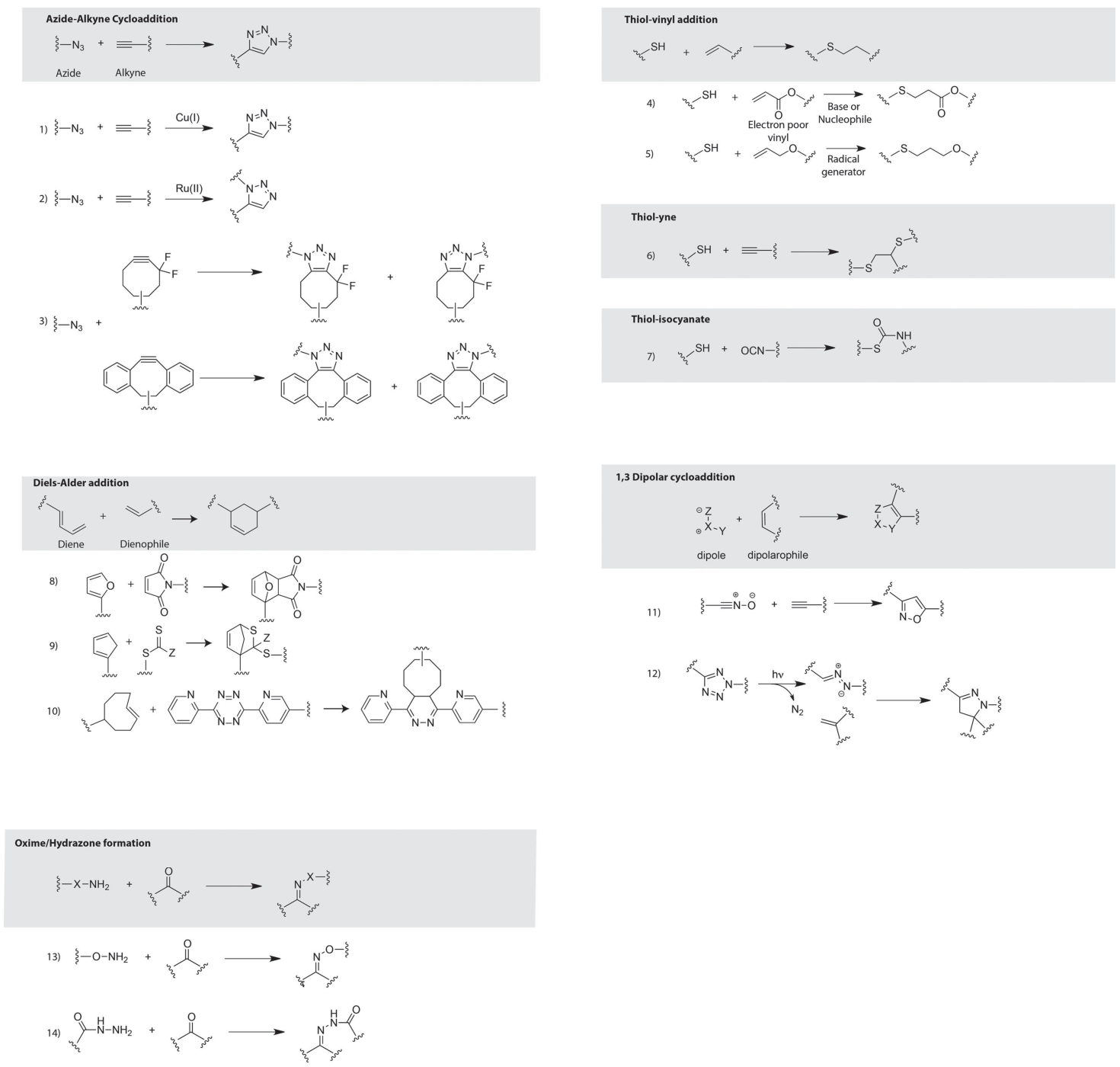

Figure 1. Overview and classification of 'click' reactions. Numerous reactions and reaction families have been identified as possessing the desired click behavior under a broad range of conditions. Each of these reactions has been applied extensively to small molecules; however, many of the most important implementations of each of these reactions have been in the materials arena including synthesis of new materials as well as modification of polymers, materials, and surfaces.

products and, despite its high heat of reaction, is typically sluggish even at elevated temperatures owing to its high activation energy. ${ }^{[10]}$ In 2002, copper(I) catalysis of the 1,3-dipolar azidealkyne cycloaddition (i.e., CuAAC) between an azide and a terminal alkyne at reaction rates sufficient to enable selective ambient temperature synthesis of the 1,4-regioisomer (Figure 1, entry 1) was described independently by Sharpless et al. ${ }^{[3]}$ and Meldal et al. ${ }^{[4]}$ The publication of these two papers occasioned the explosive growth of click chemistry as a valuable concept in materials science, and the CuAAC reaction became the prevalent click reaction in the literature, often being referred to as the "click" reaction. The use of this term to refer to the CuAAC reaction owes both to the timing of the discovery of the $\mathrm{Cu}(\mathrm{I})$ catalysis and to the ubiquitous implementation of this reaction owing to its inherent advantages. The lack of side products and the relative independence of the reaction rate on the alkyne and azide concentration have enabled it to be broadly used in coupling of even very dilute functional groups.

Although $\mathrm{Cu}(\mathrm{I})$ may be obtained directly from the utilization of $\mathrm{Cu}(\mathrm{I})$ salts and coordination complexes, ${ }^{[11,12]}$ the thermodynamically unstable $\mathrm{Cu}(\mathrm{I})$ either disproportionates to $\mathrm{Cu}(\mathrm{II})$ and $\mathrm{Cu}(0)$ or is often oxidized to $\mathrm{Cu}(\mathrm{II})$. Moreover, when $\mathrm{Cu}(\mathrm{I})$ halides are employed as azide-alkyne cycloaddition catalysts in organic solvents, significant amounts of undesired side-products are generated. ${ }^{[13]}$ Consequently, the $\mathrm{Cu}(\mathrm{I})$ species necessary for the CuAAC reaction is often generated in situ either by employing $\mathrm{Cu}(\mathrm{II})$ in conjunction with a reducing agent such as ascorbate, ${ }^{[3]}$ or via the comproportionation of $\mathrm{Cu}(\mathrm{II})$ and $\mathrm{Cu}(0) \cdot{ }^{\left[{ }^{[3]}\right.}$ Additionally, 1,2,3-triazoles and other compounds have been employed as stabilizing ligands for $\mathrm{Cu}(\mathrm{I})$, inhibiting the oxidation and disproportionation of the ion while retaining its catalytic activity. ${ }^{[14]}$ 
An alternative catalyst to $\mathrm{Cu}(\mathrm{I})$ for azide-alkyne cycloaddition is ruthenium(II). ${ }^{[15]}$ Interestingly, whereas CuAAC yields the 1,4-regioisomer cycloaddition product between an azide and a terminal alkyne, catalysis by $\mathrm{Ru}(\mathrm{II})$ exclusively results in the 1,5-disubstituted 1,2,3-triazole regioisomer (Figure 1, entry 2). ${ }^{[16]}$ Moreover, $\mathrm{Ru}(\mathrm{II})$ is able to engage internal alkynes in catalysis and thus provides a route for the synthesis of fully substituted 1,2,3-triazoles. As 1,2,3-triazoles are $\pi$-conjugated, $\mathrm{Cu}(\mathrm{I})$ - and $\mathrm{Ru}(\mathrm{II})$-catalyzed azide-alkyne cycloadditions have been used to fabricate regioregular polymeric materials with extended $\pi$-conjugation of varying chemical and photophysical properties. ${ }^{[17,18]}$

Owing to the cytotoxicity associated with $\mathrm{Cu}(\mathrm{I})$, several groups have endeavored to minimize the copper concentration while maintaining high reaction rates. ${ }^{[19]}$ Utilizing ring strain and chemical modification of the alkynyl moieties, sufficient cycloaddition reaction rates at room temperature are achievable without copper catalysis. ${ }^{[20]}$ By employing fluoro-substituted cyclooctynes that combine ring strain and electron-withdrawing fluorine substituents, Bertozzi et al. were able to effect rapid $[3+2]$ cycloaddition with azides in the absence of a catalyst (Figure 1, entry 3). ${ }^{[21-23]}$ Conversely, Boons et al. exclusively utilized strain-promoted cycloaddition with dibenzocyclooctynes; by incorporating $\mathrm{sp}^{2}$ centers to the cyclooctyne ring (Figure 1 , entry 3 ), similar reaction rates to those attainable by difluorocyclooctynes were achieved. ${ }^{[24,25]}$ Moreover, the synthetic accessibility of these aryl-functionalized cyclooctynes makes them particularly attractive for catalyst-free cycloaddition reactions with azides. ${ }^{[22,26]}$ Simple electron-deficient alkynyl groups, such as alkynyl esters, ${ }^{[27]}$ amides, ${ }^{[28]}$ and sulfones, ${ }^{[29]}$ have also been employed to effect catalyst-free azide-alkyne cycloaddition; however, the rapid addition reaction of amines to sulfonyl alkynes ${ }^{[30]}$ suggests that the reaction orthogonality of these systems may be compromised.

In addition to $\mathrm{Cu}(\mathrm{I})$ toxicity, another disadvantage of the CuAAC reaction is the potential difficulty in handling the azides. Under various conditions, such as UV irradiation for extended periods, certain azide compounds are known to explosively decompose. ${ }^{[31]}$

The canonical click reaction, the azide-alkyne cycloaddition, has traditionally been recognized as an irreversible reaction where the product 1,2,3-triazole is chemically inert and thermally stable. However, Bielawski and coworkers recently described the ability of mechanical force to break the 1,2,3-triazole functional groups into their constituent precursors. ${ }^{[32]}$ By subjecting to ultrasound, they demonstrated the mechanochemical transformation of a triazole into its azide and alkyne precursors, indicating that the alkyne-azide 1,3-diploar cycloaddition is a mechanically reversible reaction. Furthermore, they demonstrated both the 1,4- and 1,5-cycloadducts would undergo this ultrasound-induced cycloreversion reaction. ${ }^{[32,33]}$

\subsection{Thiol-X Click Reactions}

Despite the popularity of the azide-alkyne cycloadditon reaction, click chemistry is not exclusively confined to that reaction; indeed, there exists a constellation of thiol reactions that have also been considered to be click reactions and that have been broadly applied in materials science (Figure 1, entries $4-7) \cdot[5,6,34,35]$ Among this thiol-X family of reactions, one particularly common thiol-based click reaction is the radical-mediated addition of a thiol to a vinyl (i.e., the thiol-ene reaction) $)^{[34]}$ (Figure 1, entry 4). Upon the introduction of radicals formed either by light or heat, this reaction proceeds via the addition of a thiyl radical to a vinyl, forming a carbon-centered radical which subsequently abstracts a hydrogen from a thiol, thereby generating the thioether product and regenerating a thiyl radical. The ideal reaction mechanism, consisting of alternating addition and hydrogen abstraction reactions, is achieved by employing electron-rich vinyl functionalities (such as vinyl- and allyl-ethers) which do not undergo homopolymerization. ${ }^{[36]}$ One notable attribute of any reaction classifiable under the click rubric is that it must be tolerant of hydrous and aerobic conditions. Radical-mediated reactions are typically unaffected by water; however, whereas conventional radical-mediated homopolymerizations are often severely inhibited by the presence of oxygen, the ability of a peroxy radical to abstract a hydrogen from a thiol imparts thiol-ene polymerizations with exceptional oxygen inhibition resistance, when performed in relatively concentrated conditions. ${ }^{[37-39]}$

The radical-mediated thiol-ene reaction is also an excellent example of the importance of reaction conditions in determining under what circumstances a reaction behaves in a manner consistent with the click paradigm. It is obvious that each of the reactions otherwise considered to be click reactions will behave in a non-ideal manner under a variety of conditions. For the case of the thiol-ene reaction, given the nature of the radical-radical termination reaction, which must occur for each radical generated, and the nature of the chain transfer reaction to overcome oxygen inhibition, it is necessary that the initiator concentration (which can be considered an upper limit for the amount of termination side products that may form), oxygen concentration and any other potential sources of chain transfer be limited to concentrations below the level tolerable for side reactions under the desired circumstances. The difficulties associated with this reaction under certain circumstances have been demonstrated and analyzed. ${ }^{[7,8]}$ However, with prudent selection of conditions, this reaction has been demonstrated to be a robust click reaction capable of bulk polymerization, ${ }^{40-42]}$ polymer modification, ${ }^{[43-46]}$ dendrimer synthesis ${ }^{[47,48]}$ polymerpolymer conjugation, ${ }^{[49-51]}$ and many others. As simple guidelines, the initiator concentration should be kept at least one if not two orders of magnitude lower than the functional group concentration (or even react in the absence of an initiator when reacting dilute functional groups), the light intensity should be uniform and not strongly attenuated, any solvents used should not be prone to chain transfer reactions, oxygen should be purged to levels well below the tolerability of side reactions, and the ene should be selected to eliminate homopolymerization reactions. ${ }^{[34]}$

Recently, the radical-mediated thiol-ene mechanism has been complemented by the thiol-yne mechanism wherein a thiol and alkyne are coreacted in a 2:1 ratio with each alkyne capable of reacting with two thiols in an alternating chain transfer and propagation process that is mechanistically equivalent to the thiol-ene reaction. ${ }^{[52-55]}$ (Figure 1, entry 6) The monothiol-yne addition product is a vinyl sulfide that is 
generally at least as reactive to thiyl radical addition as the initial alkyne; however, for certain alkyne structures such as cyclooctynes, no second thiol addition occurs. ${ }^{[53]}$ As indicated, this idealized thiol-yne mechanism parallels that of the thiolene mechanism. Thus, after complete reaction, each alkyne functional group has combined with two thiols to generate a dithioether, thus establishing the alkyne as a difunctional group in thiol-yne reactions and resulting in increased network connectivities afforded by thiol-yne polymerizations when compared with thiol-ene polymerizations. The thiol-ene reaction is rapid, readily proceeds at ambient conditions, and can be photoinitiated, making it a highly versatile click reaction. Unfortunately, the radical-mediated thiol-ene reactions can give rise to significant bimolecular termination products that may limit its utility for end-group coupling between macromolecules when the endgroups are dilute. ${ }^{[8]}$ In particular, the relative amount of radical initiator to thiol and ene functional groups should be minimized to limit the radical-radical coupling reactions that generally result in undesired side products. Further, internal vinyl groups have generally been found to react more sluggishly and do not readily achieve the yields commonly attributed to click reactions.

Thiol-vinyl addition click reactions are not exclusively limited to a radical mechanism. Click reactions necessarily proceed as co-reactions where each of the reactants are consumed at equimolar consumption rates. Thus, whereas the radical-mediated copolymerization of thiols and electronpoor vinyls is not considered a click reaction owing to the homopolymerization of the vinyl functionality, both the base and nucleophile-mediated Michael addition between thiols and electron-poor vinyl groups such as acrylates, maleimides, and vinyl sulfones can be readily categorized as click reactions (Figure 1, entry 5). ${ }^{[34]}$ The nucleophile-mediated thiol-Michael addition proceeds via a completely different pathway from traditional base-catalyzed thiol-Michael addition. ${ }^{[56-58]}$ In the nucleophile-mediated mechanism, the nucleophilic addition towards an electron-deficient vinyl group initially generates a carbon-centered anion which acts as a strong base and deprotonates a thiol to generate a thiolate anion, thus initiating the thiol-Michael addition catalytic cycle. The thiol-Michael addition reaction is readily catalyzed by small amounts of bases or even ppm levels of appropriate alkyl phosphine nucleophiles and is not subject to the same concerns of termination-induced side products that arise for the radical-mediated thiol-ene reaction.

Additional thiol-based addition chemistries that have been described as conforming to the criteria for click classification include simple nucleophilic attack of a thiol to a halide, such as the 'thio-bromo' substitution ${ }^{[59]}$ and the 'thiol-para-fluorine' substitution (i.e., the attack of a thiol to a perfluorinated phenyl group at the para position). ${ }^{[6]}$ An organic base is typically employed with these reactions such that, upon reaction with the hydrogen halide by-product, an insoluble hydrohalide salt is generated, driving the reaction to completion. Thiol-isocyanate additions have also been classified as thiol-click reactions owing to their high yields and moderate reaction conditions to form thio-urea products (Figure 1, entry 7). ${ }^{[61]}$ This classical reaction has been widely utilized in polymer chemistry for decades. The breadth of reactions that are possible for the thiol moiety rep- resents in many ways the greatest strength and weakness of the thiol-X family of click reactions. The strength is that, once obtained, the thiol can be used to react with many substrates that are widely available while the weakness is a potential loss of orthogonality in the reactions. This lack of orthogonality can largely be overcome by careful selection of the reaction order, catalysts, and other conditions as needed to eliminate the undesired reaction pathways.

\subsection{Diels-Alder Cycloaddition}

The Diels-Alder cycloaddition is one of the most powerful and widely used reactions in organic synthesis and has been employed extensively in polymer chemistry applications such as block copolymer synthesis, formation of highly cross-linked networks, and self-healing materials. ${ }^{[62-66]}$ The Diels-Alder reaction, first described by Otto Diels and Kurt Alder in $19288^{[67]}$ is a [4+2] cycloaddition reaction between a diene and a dienophile to form a cyclohexene adduct (Figure 1, entries 8-10). One attractive characteristic of the Diels-Alder reaction that has been exploited in polymer chemistry is its thermal reversibility, which can be utilized in temperature-controlled reversible polymer network formation, particularly in self-healing applications. ${ }^{[68]}$ However, typical Diels-Alder [4+2] cycloaddition reactions require elevated temperatures, often in excess of $100{ }^{\circ} \mathrm{C}$, for extended times to achieve equilibrium (and often incomplete as dictated by the reversibility) conversion; these conditions for achieving high yields do not readily satisfy the click chemistry criteria and limit the consideration of DielsAlder reactions of many reactants as click reactions.

An alternative approach to Diels-Alder click chemistry is the inverse electron demand Diels-Alder (IVED-DA) reaction between a tetrazine and a strained alkene or alkyne (Figure 1, entry 10). ${ }^{[69]}$ This reaction initially proceeds via a [4+2] cycloaddition, upon which the release of $\mathrm{N}_{2}$ by a retro-[4+2] reaction yields a stable dihydropyridazine or pyridazine. This reaction, first reported and described as an bioorthogonal reaction by Fox et al. in $2008,{ }^{[70]}$ proceeds rapidly even at extremely low concentrations.

\subsection{Tetrazole Cycloaddition \& Nitrile Oxide Cycloaddition}

In addition to the [4+2] cycloaddition, the 1,3-dipolar cycloaddition is another popular cycloaddition reaction (Figure 1, entries 11 and 12). One successful example is the photo-triggered 1,3-dipolar addition between 2,5-diaryl tetrazoles and alkenes. Upon irradiation, a 2,5-diaryltetrazole releases $\mathrm{N}_{2}$ to afford a nitrile-imine which can subsequently participate in a 1,3-cycloadditon with an alkene. In 2008, Lin et al. utilized this photoactivated, tetrazolebased 1,3-dipolar cycloaddition for protein labeling by reacting a tetrazole-functionalized protein with acrylamide within few minutes of UV irradiation, demonstrating the bio-orthogonality, efficiency, and speed of this reaction. ${ }^{[11]}$ Another example of click-like 1,3-dipolar cycloaddition reactions is the reaction of a nitrile oxide with an activated alkene or alkyne. Carell et al. used nitrile oxides as strong electrophiles and norbornenes as strained alkenes in DNA modification, and obtained rapid and complete reaction conversion at ambient temperature. ${ }^{[72]}$ It should be noted that the 
high reactivity of nitrile oxide species might result in reaction with many nucleophile types, such as thiols and amines, resulting in a corresponding loss of selectivity and orthogonality for this reaction in many applications. ${ }^{[73]}$

\subsection{Oxime/Hydrazone Formation}

The condensation reaction between aldehydes/ketones and nucleophilic amines is a classic reaction in carbonyl chemistry, where the resulting imine bond is reversible, a property that is strongly dependent on the structure of the amine and the carbonyl. In general, aldehydes are more reactive than ketones, mainly due to steric effects. Moreover, the amine structure can be optimized by the $\alpha$-effect, as is observed in modified amines such as hydroxylamine and hydrazide compounds, which afford oxime and hydrazone adducts, respectively, upon condensation with a carbonyl (Figure 1 , entries 13 and 14). ${ }^{[74,75]}$ The oxime/hydrazone formation reaction is chemoselective and compatible with other functional groups in biomolecules, and the rate of this reaction can be enhanced by protic or nucleophilic (e.g., aniline) catalysts. Maynard et al. utilized this reaction to conjugate $N$-levulinyl lysine-modified bovine serum albumin to aminooxy-terminated synthetic polymers within 30 min. ${ }^{[76]}$ The oxime/hydrazone formation provides a mild and rapid approach for bioconjugate preparation; however, the potential instability of this linkage should be taken into consideration.

\subsection{Click Reaction Orthogonality: Sequential and Simultaneous Reactions}

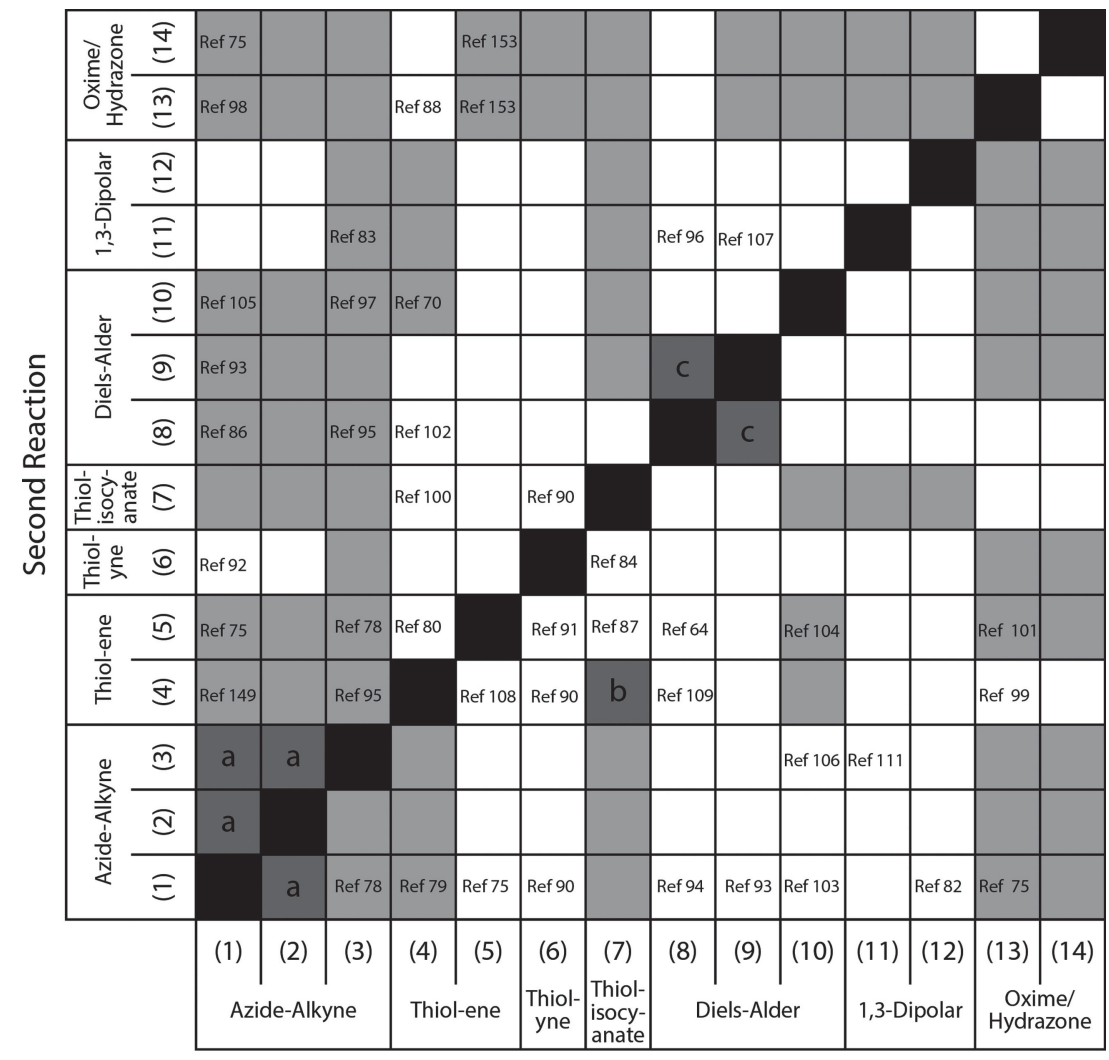

First Reaction

Figure 2. Feasibility table for performing orthogonal, sequential click reactions. Light gray cells represent reactions that are feasible under a relatively wide range of conditions while white cells are feasible but limited to a narrow range of reaction conditions, including potentially requiring sequential addition of reactants. Dark gray cells represent problematic and difficult sequential reactions (see footnotes for specifics) to perform in a single vessel, often due to a product or catalyst from the first reaction potentially participating in the second reaction. The reaction numbers in the table correspond to the specific reactions presented in Figure 1 for the various click reactions. References cited are meant to provide examples of substrates and conditions for performing these specific combinations of click reactions. ${ }^{[6,70,75,78,82-111]}$ Notes: A. If the $\mathrm{Cu}(\mathrm{I})$ or $\mathrm{Ru}(\mathrm{II})$ catalyst remains from the first reaction, it will catalyze the second reaction upon generation or addition of the second reaction species. B. The remaining base from the first reaction also will catalyze the second reaction if not removed. C. The product of the first Diels-Alder reaction can also participate as a dienophile in the second Diels-Alder reaction.
Since click reactions have been developed and applied across many fields, the implementation, either simultaneously or sequentially of a combination of two or more click reactions, is a critical issue. While click reactions are generally purported to be orthogonal to other reactions, the extent of the orthogonality depends greatly on the nature of the substrate; the reaction conditions including reactants, catalysts, and other species; and the possible other reactions. If two reactions are completely orthogonal, such as the CuAAC and oxime formation reactions, they proceed simultaneously without any interference under a broad range of conditions. The number of pairs of these ideally orthogonal reactions is limited, however. The most obvious limitation is that there are common substrates for many of these reactions, e.g., the yne functional group that is capable of proceeding via the CuAAC reaction, the radical-mediated thiol-yne reaction and via thiol-yne Michael addition, all depending on the specific yne structure, the catalyst and other reaction conditions. However, even under circumstances such as this one, the selection of appropriate reaction order and conditions enables the successful employment of multiple click reactions. For example, the SPAAC reaction has substrate-selectivity for alkynes, ${ }^{[77,78]}$ while the thiol-yne reaction does not. Here, the combination of these two reactions requires that the SPAAC be implemented first followed by the radical thiol-yne reaction.

As a broad, general guideline to aid in the selection of possible orthogonal reaction pairs, Figure 2 presents an attempt at identifying the pairs of click reactions which are orthogonal for purposes of sequential, controllable initiation in a single reaction vessel and those that are not, including references to identify specific enabling conditions and examples for performing the orthogonal reactions in the order indicated, where such examples exist. Cells that are light gray indicate that the sequential reactions, in the specified order are broadly feasible without 
severe limitations on the conditions or substrates and without necessitating additional reaction steps such as functionalization or deprotection in between the two click reactions. Generally, all substrates for these light gray cell combinations of sequential reactions are expected to be able to be present simultaneously at the start of the reaction, and sequential catalyst generation would be used to facilitate the sequential reactions. Cells that are white represent sequential reactions that are possible but can only be performed under a limited range of conditions, including potentially requiring addition of reactants in between the two click reactions. For example, in the thiol-ene (reaction 5)/thiol-yne (reaction 6) combination reaction, if the ene and yne are simultaneously present, both will react in the initial reaction. However, if the radical thiol-ene reaction is performed first with a stoichiometric excess, that stoichiometric excess will persist after the first reaction and can be further reacted in a second step after the desired yne is added into the reaction mixture.

In contrast, dark gray cells represent sequential reactions that are difficult to perform in a click manner within a single reaction vessel. For example, in the case of the thiol-Michael (reaction 4)/thiol-isocyanate (reaction 7), the same base catalyst used to initiate the thiol-isocyanate reaction could catalyze the thiolMichael addition reaction in an uncontrolled manner upon subsequent addition of the electron deficient vinyl necessary for the thiol-Michael reaction. For such a circumstance, neutralization of the base catalyst following the thiol-isocyanate reaction could be used to prevent immediate thiol-Michael addition.

This table was constructed based on the broad mechanisms known for each specific reaction and reactants listed in Figure 1. References are included in numerous cells to indicate examples of the implementation of each of these pairs of sequential click reactions; however, it is obvious that there are a large number of cells without examples of these sequential reactions as well. Clearly, this table attempts to classify these reactions broadly, and in both directions variations are possible depending on the specific substrates and conditions. Though limited, there will likely be conditions, time scales, and substrates for which orthogonality is achieved for those pairs of reactions listed as problematic or non-orthogonal. Also, under some circumstances and conditions, pairs of reactions presented as orthogonal may very well behave in a non-ideal manner. Ultimately, this analysis provides initial guidance for performing sequential click reactions as utilized widely in polymer functionalization, block copolymer synthesis, surface modification and dendrimer synthesis but should be implemented with caution due to the sensitivity of each reaction to the specific conditions. ${ }^{[79-81]}$ It is expected that many of the heretofore unexplored combinations of click reactions would be beneficial in various areas of materials science, and we anticipate their successful development and implementation.

\section{Incorporating Click Targets into Materials}

\subsection{Synthetic Handles for Click Targets in Controlled Radical Polymerization}

Controlled radical polymerization chemistry is a powerful tool in polymer synthesis, affording excellent control over the molecular weight, molecular weight distribution, architecture, and properties of the generated polymers. Three commonly used controlled radical polymerization reactions are, nitroxide-mediated radical polymerization (NMP), ${ }^{[12]}$ atom transfer radical polymerization (ATRP), ${ }^{[113,114]}$ and reversible addition fragmentation chain transfer polymerization (RAFT). ${ }^{[15]}$ These techniques greatly change the strategy of polymer preparation and enable facile synthesis of welldefined polymers with diverse structures and functions. Although the development of controlled, living radical polymerizations and click chemistries have proceeded along parallel trajectories, the past several years have seen intriguing convergences between these powerful synthetic techniques in materials chemistry, enabling the facile creation of otherwise synthetically intractable polymeric molecular architectures. ${ }^{[116-121]}$

One way to introduce click reactions into ATRP- and RAFTgenerated polymers is via the incorporation of click reactants as pendant groups affixed to the polymer backbone. The most commonly used approach is the nucleophilic attack by an azide anion to a terminal bromide on polymers prepared by ATRP. ${ }^{[122]}$ This reaction is typically performed by the terminal bromide on an ATRP-formed polymer with reacting excess sodium azide to ensure quantitative substitution. Alternatively, owing to the orthogonality of azides to the ATRP reaction, azide groups can also be incorporated in monomers as pendant groups prior to polymerization. Matyjaszewski and coworkers were the first to demonstrate sequential ATRP and CuAAC click reactions using this approach. ${ }^{[122]}$ By employing 3-azidopropyl methacrylate as a monomer in an ATRP reaction, they obtained polymers with both low polydispersity and pendant azide functionalities. Subsequently, this azide-bearing polymer was coupled with alkyne-terminated molecules via a CuAAC click reaction.

Cyclopentadiene, a highly reactive diene, moieties can be similarly incorporated into an ATRP-generated polymer using sodium cyclopentadiene ( $\mathrm{NaCp}$ ) via simple nucleophilic substitution, as was demonstrated by the functionalization of poly(ethylene glycol) and poly(styrene). ${ }^{[123]}$ However, the strong basicity of $\mathrm{NaCp}$ precludes its application in the preparation of ester-functional polymers such as poly(acrylates) and poly(methacrylates). ${ }^{[124]}$ To overcome this limitation, Inglis et al. developed a methodology utilizing nickelocene $\left(\mathrm{NiCp}_{2}\right)$ to efficiently convert terminal bromides into $\mathrm{Cp}$ functional groups, ${ }^{[125]}$ which were subsequently employed as Diels-Alder reactants whose reaction proceeded rapidly and to completion in a few minutes, even at ambient temperature.

The utilization of end groups on polymers generated via RAFT polymerization has also been employed to facilitate subsequent click reactions. For example, the base-catalyzed hydrolysis of terminal dithioester groups has been employed to readily form terminal thiols, which can subsequently be utilized as click reactants following RAFT polymerizations. ${ }^{[44]}$ In 2006, Quemener et al. first described the utilization of a dithioester as a dienophile, in conjunction with cyclopentadiene as diene, in a Diels-Alder cycloaddition reaction. ${ }^{126]}$ Thus, the highly electron-withdrawing dithioester not only acted as a controlling agent in RAFT polymerization but also could participate directly in Diels-Alder addition as 


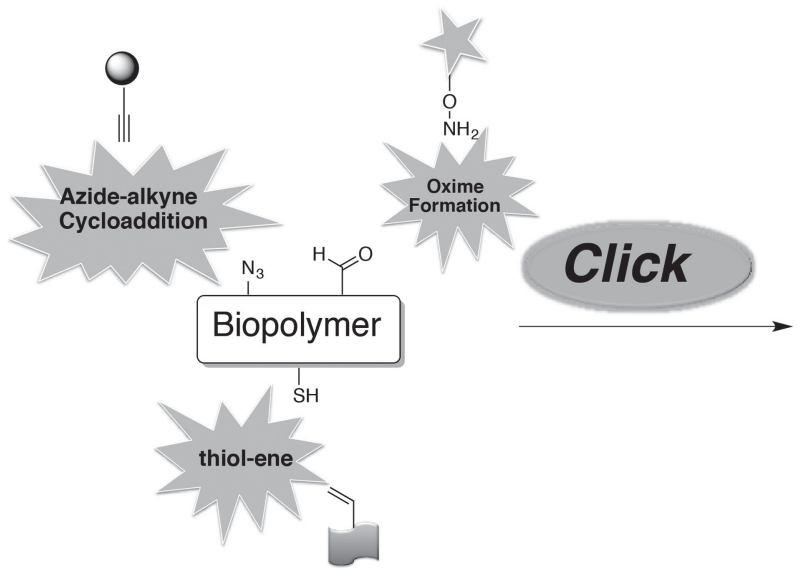

Figure 3. Click reactions for biopolymer modification.

an efficient dienophile after the RAFT polymerization (see Figure 1, entry 9).

\subsection{Click Targets on Biopolymers: Oligopeptides, Proteins, and DNA}

Since the emergence of chemical biology, increasing attention has been directed towards the utilization of click chemistry in the conjugation and functionalization of biorelated polymers such as proteins, oligo/polysaccharides, and oligonucelotides. Here, various aspects of the click reaction have further elevated importance, including the orthogonality of the reaction and the ease with which the reaction can be performed under biorelevant conditions. Often the conditions for performing biofunctionalization reactions are such that a vast array of other species are present with which the desired reactions must be orthogonal, and toxicity of the reaction mixture, including any necessary catalysts, would prevent implementation. Ultimately, then, these reactions must be highly chemical selective, react rapidly under physiological conditions at low concentration, and be non-toxic (i.e., biocompatible). ${ }^{[127]}$

Several click reactions, with judicious selection of the specific reactants and catalytic conditions, are able to achieve these requirements and are used widely in bioconjugation reactions, e.g., in protein modification (Figure 3). Bioconjugation and biofunctionalization click approaches often take advantage of naturally occurring, highly reactive functional groups that arise in biopolymers. For example, amines and thiols, present in lysine and cysteine, respectively, are used in peptide/protein modification, while a variety of reactions involving alcohols and thiols have been used to functionalize oligo/polysaccharide compounds. Additional clickable functional groups, such as azides and alkynes, have been introduced post-synthetically by chemical modification; however, an exciting and powerful approach to incorporation of clickable units involves genetic encoding and inclusion of non-natural amino acids. These non-natural, clickable functional groups are subsequently used to enable peptide/protein modification. As one example of such an approach, in 2007, Bertozzi and coworkers utilizing ring strain promoted azide-alkyne cycloaddition to modify lipoyl domain of full-length E2p protein with different tags. ${ }^{[128]}$

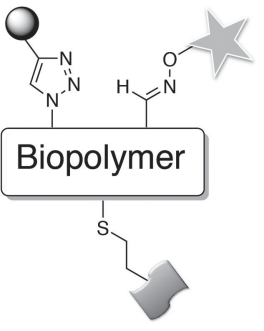

\subsection{Photomediated Click Reactions}

One intriguing research direction that has emerged with the maturation of click chemistry is that of 'photo-click' chemistry, where the reaction proceeds upon UV or visible light irradiation. ${ }^{[129]}$ Photochemistry enables unparalleled spatial and temporal control over the reaction, allowing for multi-dimensional patterning via judicious irradiation schemes. Thus, the combination of facile photo-patterning with the reaction specificity and robustness of click chemistry is particularly powerful. Owing to the ready availability of radical photoinitiators, the radical-mediated thiol-ene and thiol-yne reaction mechanisms are the archetypical photo-click chemistries. Another appropriate photo-click strategy is that of using light to generate clickable reactive function groups. In 2009, Vopik and co-workers first fulfilled this strategy in click chemistry, they developed a method to generate cyclooctynes through photochemical decarbonylation of cyclopropenones. ${ }^{[130]}$ The generated cyclooctynes subsequently and rapidly underwent a $\mathrm{Cu}$-free azide-alkyne coupling reaction and were finally used as a selective in situ labeling technique in a living organism. In 2012, the same group introduced light-induced hetero-Diels-Alder cycloaddition as a photoclick reaction. ${ }^{[131]}$ They used photochemical dehydration of 3-hydroxy-2-naphthalenemethanol derivatives to produce orthonaphthoquinone methides (oNQMs) which is a hetero-diene that undergoes facile cycloaddition with vinyl ethers or enamines to yield photostable cycloadducts. They applied this phototriggered Diels-Alder reaction to form a high-density patterned derivatization of polymer-brush-coated surfaces. Also, this photo-triggered hetero-Diels-Alder reaction is orthogonal to other click reactions, so it allows for parallel or sequential fabrication of surfaces combing this reaction with other click reactions. Recently, Barner-Kowollik and coworkers also developed a photo-triggered Diels-Alder reaction using photogenerated hydroxyl-o-quinodimethane as the diene through photoisomerization of o-methylphenyl ketone or aldehyde, then reacted with highly active dienophiles such as maleimides to yield a photostable Diels-Alder product. ${ }^{[132]}$ Photoinitiated click reactions have also been introduced into oxime ligation, enabling it to be used for surface patterning. ${ }^{[133]}$ Here, the nitrosobenzaldehyde was used as a substrate generated from the photocleavage of o-nitrobenzyl derivatives, then reacted with hydroxylamine to form an oxime bond. Since this reaction was triggered by light, it enabled spatial control of oxime formation, which was confirmed by specific attachment of aminooxy functionalized biomolecules.

Although the above methods for the photo-generation of reactive functional groups that subsequently undergo efficient click reactions all enable numerous applications such as surface modification and bioactive labeling, it is important to note that 




Figure 4. Select applications of click chemistry in materials science.

these systems, other than the thiol-ene/yne reactions, have, at best, one reaction event occur per absorbed photon. Conversely, a significant amplification ratio results when one photon leads to many reaction events, as is often observed in radical-mediated reactions such as the thiol-ene reaction where hundreds to tens of thousands of thiol-ene coupling events can occur per radical generated (i.e., directly related to the photon absorption). Recently, photo-generation of $\mathrm{Cu}(\mathrm{I})$ has been employed for the in situ and spatiotemporally controlled reduction of $\mathrm{Cu}(\mathrm{II})$, enabling photo-CuAAC. ${ }^{[134-137]}$ The mechanism for the reaction confinement could not be confirmed; however, it is likely attributable to the association of $\mathrm{Cu}(\mathrm{I})$ to the alkyne-functionalized monomer during the course of the $\mathrm{CuAAC}$, the ligandization of the $\mathrm{Cu}(\mathrm{I})$ with the triazole product, or the rapid degradation of $\mathrm{Cu}$ (I) once it diffuses out of the irradiated area. As the development of photochemical methods and click chemistry proceeds, more attention will likely be focused on improving spatial and temporal reaction control and further will be implemented into photo-controlled materials synthesis and photo-controlled conjugation or release of target molecule to the materials.

\section{Click Reaction Applications in Materials Science}

\subsection{Polymer/Materials Synthesis and Modification}

Click chemistry provides a powerful and versatile tool for materials synthesis owing to its simplicity, selectivity, efficiency, and tolerance of various functional groups. Consequently, a wide range of controlled-architecture materials have been synthesized through various click reactions, including block polymers, micelles, dendrimers, gels, and networks (Figure 4) Many click reactions have also been used as effective tools to modify polymers or materials with a variety of functional components, thereby adding unique properties and functions to the previous materials. As previously mentioned, controlled radical polymerization is a convenient and rapid method for the preparation of polymers with well-defined molecular weights and properties which, when combined with click chemistry, not only expands the diversity of protocols for material synthesis but also achieves multi-functionalization of materials simply and efficiently.

An alternative and elegant strategy to incorporate clickable groups on polymer chains is to functionalize the polymerization initiator with a click reactant (such as an azide or alkyne), thus avoiding the necessity for post-polymerization modification prior to ligation. One example of this strategy was developed by Haddleton and co-workers, who employed an azide-functionalized initiator for the polymerization of methyl methacrylate via an ATRP reaction. ${ }^{[138]}$ After polymerization, a terminal alkyne was added to the azide through $\mathrm{CuAAC}$, with quantitative conversion. In 2006, Barner-Kowollik and co-workers employed clickable groups into RAFT initiator structures by synthesizing azide- and alkyne-modified, conventional RAFT agents to mediate the polymerization of styrene and vinyl acetate. ${ }^{[26]}$ Subsequently, these two clickable homopolymers were coupled together to form narrow polydispersity poly(styrene)-blockpoly(vinyl acetate) copolymers. As azide and alkyne click reactants are inert during ATRP and RAFT polymerization, combining click chemistry with ATRP/RAFT has evolved into a versatile approach to well-defined copolymer synthesis. Besides the widely used azide and alkyne functional groups, other clicktype reactants, such as aldehydes and aminooxys, have been utilized for the facile synthesis of complex polymer architectures, such as star copolymers, when combined with living radical polymerization. For example, Lu et al. prepared a macroRAFT, poly( $N$-isopropylacrylamine)-based initiator by an 'arm first' approach which was then crosslinked with an aldehydecontaining divinyl compound to form an aldehyde functionalized core, then PEG-terminated aminooxy reacted with aldehyde to produce a miktoarm star copolymer. ${ }^{[139]}$ One interesting thing is this star copolymer exhibited thermally-induced micellization behavior owing to the reversible low critical solution temperature (LCST) behavior of poly( $N$-isopropylacrylamine). Compared with linear polymer synthesis, cyclic polymers represent a distinctive materials class which benefits greatly from the use of click reactions. ${ }^{[140]}$ The most common and straightforward synthetic approach to cyclic polymers utilizes a highly efficient reaction to connect two reactive ends into a cycle, making click chemistry an ideal selection for the polymer ring closure and formation. ${ }^{[141]}$ As one example of this approach, Grayson et al. synthesized a telechelic polystryrene that has an alkyne and azide as the two end groups, with cyclization achieved by CuAAC with nearly quantitative yields. ${ }^{142]}$

Although the simplicity and efficiency of click chemistry has been extensively explored in linear/cyclic block copolymer synthesis, it has also found utility as an effective tool in preparation of materials with complex architectures. Nischang et al. employed radical-mediated thiol-ene click chemistry to functionalize hierarchically structured cubic polyhedral silesquioxanes. ${ }^{[143]}$ The basic core structure was built through radical initiated polymerization of polydedral vinylsilesquioxane to yield a nanoporous structure containing residual vinyl groups. Subsequently, the thiol-ene reaction was used to functionalize the surface with thiolated PEG or thioglycolic acid, to afford hybrid organic/inorganic nanoporous materials. Cheng and $\mathrm{He}$ also introduced thiol-ene click chemistry to form various hybrid structures based on functionalization of polyhedral oligomeric silsesquioxane (POSS) cages, leading to structures such as Janus particles and giant gemini surfactants. ${ }^{[144-147]}$ The gemini surfactants are amphiphiles which consist of two hydrophilic POSS heads and two hydrophobic polystyrene tails. Additionally, these two polymer chains were covalently connected and 


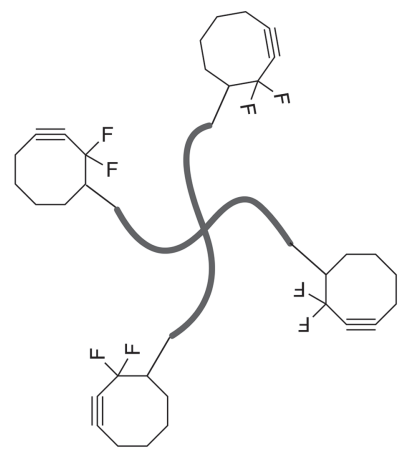

Tetra-PEG-cyclooctyne

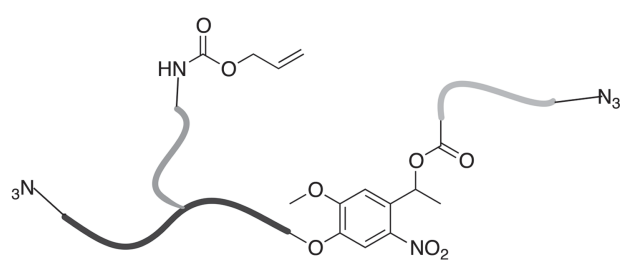

Di-azide with cleavable backbone

\section{Gel formation: SPAAC}

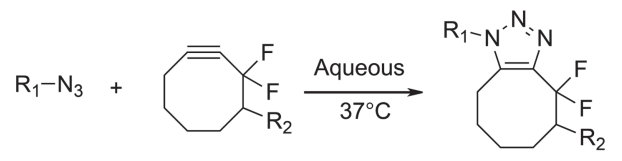

\section{Gel chemical patterning: thiol-ene}

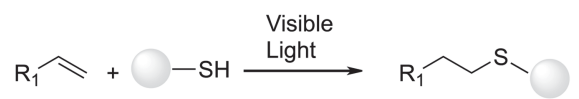

\section{Gel mechanical patterning: photodegradation}<smiles>[R]Oc1cc([N+](=O)[O-])c(C(C)OC([R2])=O)cc1OC</smiles><smiles>[R]Oc1cc([N+](=O)[O-])c(C(C)=O)cc1OC</smiles>

Figure 5. Photo-mediated coupling and degradation for triggered, patterned chemical and mechanical manipulation of hydrogel properties. Adapted with permission. ${ }^{150]}$ Copyright 2011, Nature Publishing Group.

exhibited self-assembly in solution. Their synthesis involved sequential thiol-ene and CuAAC "click" reactions to graft hydrophobic/hydrophilic polymer onto POSS cages to form an amphiphile. ${ }^{[148]}$ Another impressive example exploiting the click philosophy to synthesize complex, highly branched polymers was described by Hawker and co-workers who used an alternating combination of thiol-ene and $\mathrm{CuAAC}$ reactions to synthesize multigeneration dendrimers in a single day. ${ }^{[149]}$ Here, the first generation dendrimer was prepared by a thiolene reaction to functionalize tris(alloxy)triazine with an azideterminated thiol. The azide groups were then reacted with allyl-functionalized alkynes, ensuring the presence of residual allylic groups for the next thiol-ene reaction. This process was rapidly repeated three times to yield the $6^{\text {th }}$-generation dendrimer within a $24 \mathrm{~h}$ period.

Click chemistry has also been applied to the formation of polymer networks. Indeed, click reactions are particularly wellsuited for the synthesis and modification of hydrogels to achieve tunable properties. The Anseth group has been a notable proponent of utilizing click reactions in hydrogels (Figure 5). By applying click reactions to form a hydrogel and subsequently using light to spatially pattern chemical functionality through photo-click and photo-cleavage reactions, they have demonstrated the ability to pattern physical characteristics in three dimensions throughout this hydrogel. ${ }^{[150]}$ Initially, they synthesized a hydrogel via a copper-free, strain-promoted azide-alkyne cycloaddition between water soluble tetracyclooctyne- and diazide-functionalized prepolymers. Once the gel was formed, thiolated fluorophores and a water-soluble photoinitiator was swollen into the gel and a photoinitiated thiol-ene reaction between the thiol and vinyl-modified lysine incorporated in the network backbone was performed. Multi-photon irradiation enabled the creation of three-dimensional biochemical patterns with micrometer-scale resolution. Another characteristic of this hydrogel was the incorporation of a photodegradable group nitrobenzyl ether moiety which was sensitive to UV light. Thus, photocleavage approach created a high level of defined shapes with precise control. This combination of multiple, orthogonal photo-click and photocleavage reactions enables fine, localized tuning of synthetic hydrogel biological, chemical, and mechanical behavior, as is necessary to generate specific microenvironments for three-dimensional culturing of multiple cell lines.

\subsection{Surface Modification, Patterning, and Lithography}

High-throughput microarray technology, an extremely useful tool for effective screening of libraries of biomacromolecules such as proteins and nucleic acids, has developed rapidly. To achieve diverse, chip-based bioassays, an ever-increasing variety of approaches have been developed to fabricate these microarrays. One such approach is photolithography, a technique which is commonly used to form micrometer-scale arrays.

Various methods have been developed to achieve efficient and rapid surface modification. Click chemistry has proven to be a versatile tool in this field owing to its distinct advantages when compared with traditional coupling methods. Nottlet et al. utilized the CuAAC reaction to modify a biodegradable polylactide (PLA) surface. ${ }^{[151]}$ After initially performing an anionic polymerization to generate an alkyne-modified surface, azide-terminated small molecules, macromolecules, and biomolecules were affixed and immobilized on this surface, altering its bioactivity against bacteria (Figure 6A). Recently, Chmielewski et al. reported applying the CuAAC 
(A)

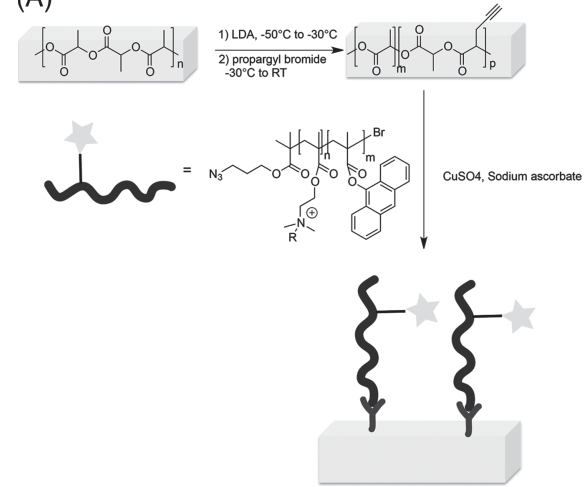

(B)

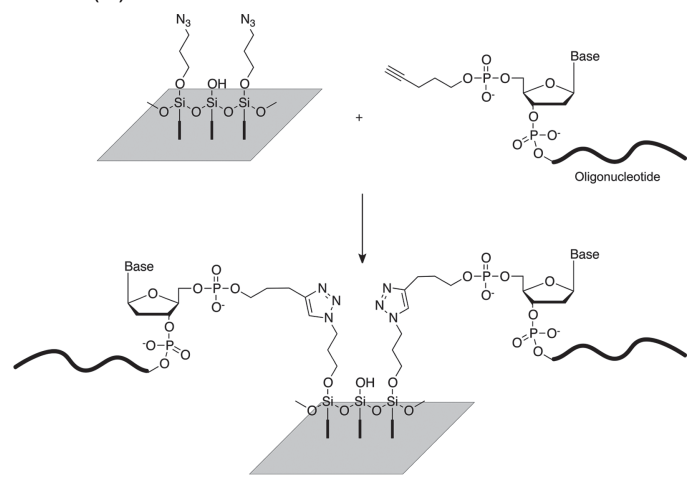

Figure 6. A) Synthesis of a clickable surface of PLA 94. Adapted with permission. ${ }^{[152]}$ Copyright 2012, Royal Chemical Society. B) Strategy for modifying a DNA sequence on an azide-functionalized glass surface. Adapted with permission. ${ }^{[151]}$

reaction to conjugated DNA onto a solid support. ${ }^{[152]}$ By modifying oligodeoxynucleotides (ODNs) with alkynyl end groups, attachment of these oligonucleotides to an azide-modified solid support was achieved via a CuAAC click reaction. Subsequently, a hybridization experiment with fluorescent complementary sequences demonstrated the success of the ODN attachment to the surface and the production of DNA microarrays (Figure 6B).
Thiol-ene click reactions comprise another class of powerful tools in imprint and lift-off lithography. In 2008, Hawker and co-workers used thiol-ene chemistry to fabricate tunable PEG- and polysiloxane-based, cross-linked elastomers. ${ }^{[42]}$ Two years later, the same group developed a versatile approach to fabricate microarrays on a hydrogel using thiol-ene chemistry. ${ }^{[153]}$ Their general procedure to fabricate the hydrogel is shown in Figure 7. Initially, molecules of interest were printed

(A)

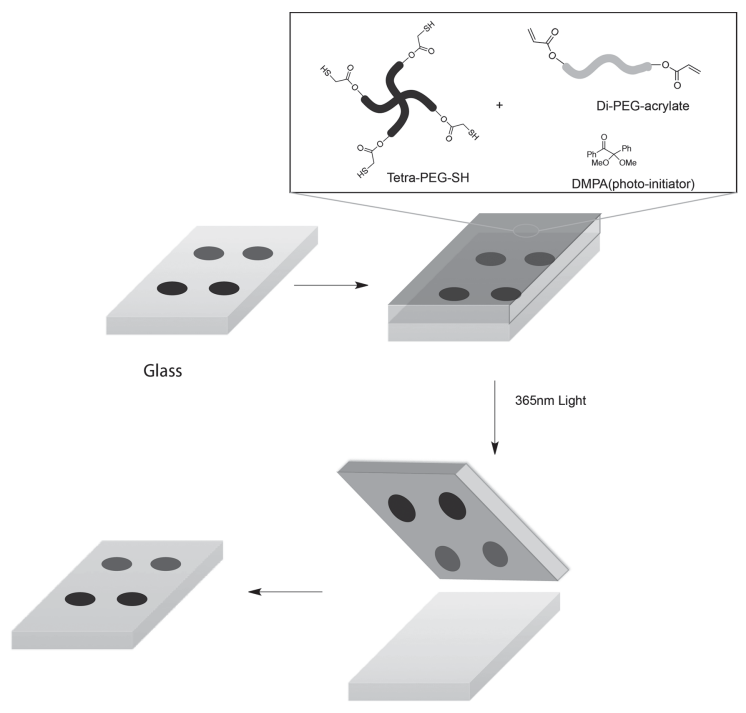

(B)


Figure 7. A) Thiol-ene-based fabrication of hydrogel microarrays, and B) direct printing of peptides with orthogonal post-functionalization on microarray. ${ }^{[153]}$ Adapted with permission. Copyright 2012, Nature Publishing Group. 
(A)

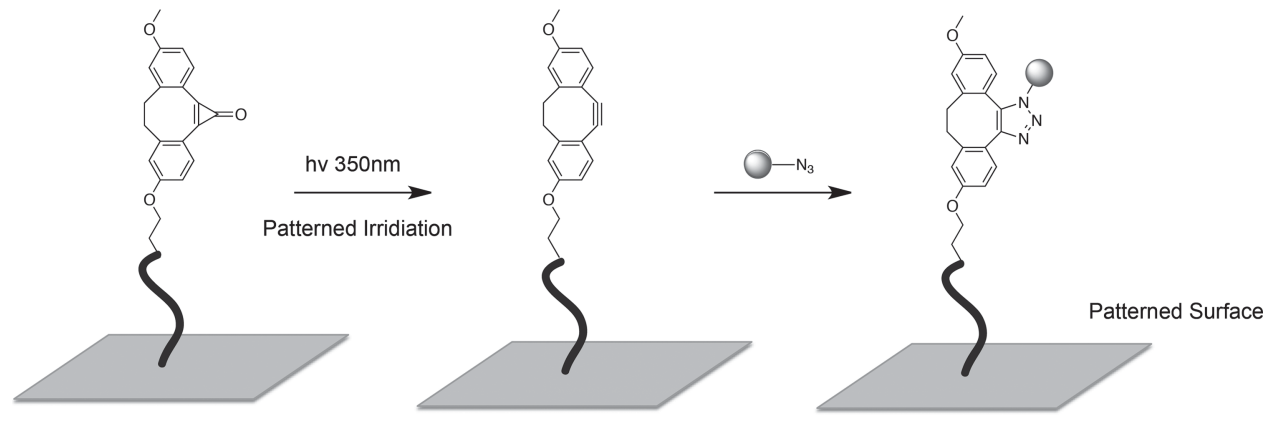

(B)
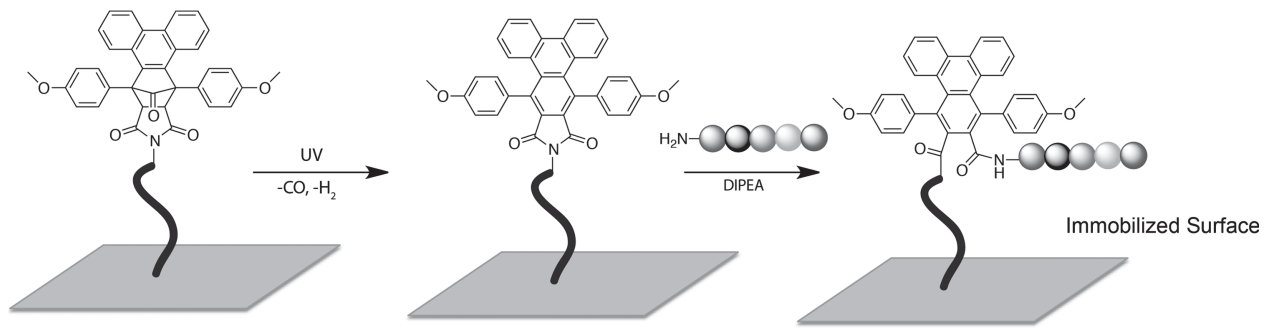

Figure 8. A) Surface modification and photopatterning using Cu-free azide-alkyne cycloaddition. Adapted with permission. ${ }^{[154]}$ Copyright 2010 , American Chemical Society. B) UV-triggered surface immobilization of an amine-containing peptide. Adapted with permission. ${ }^{[156]}$

on a surface using a microarray spotter, then a thiol-ene resin was poured over the surface and photopolymerized to form a cross-linked hydrogel which, when lifted off the surface, retained the molecular array. Owing to the orthogonal nature of the thiol-ene reaction, a wide range of molecules could be using in the microarray. This general strategy also allows for other chemistries to produce functionalized microarrays, such as azide-alkyne, NHS-active ester, and hydrazone chemistry. They demonstrated their strategy using cysteine-containing peptides printed on the surface and transferred to the hydrogel as a microarray, then postsynthetic modification was used to give a fluorescence image using rhodamine- $\mathrm{NH}_{2}$ as a nucleophile in NHS-active ester chemistry.

Surface chemistry modification has been vastly improved using various photo-click strategies; one common approach uses photoactive substrates as precursors attached to the surface followed by patterned irradiation to generate active species that undergo sequential click reactions. Popik and co-workers utilized UV irradiation to convert cyclopropenone-masked cyclooctynes into cyclooctynes which subsequently reacted with fluorescent azides through copper free azide-alkyne cycloaddition to yield a patterned surface (Figure 8A).[154] Recently, the Barner-Kowollik group reported a similar strategy to generate surface patterns using a phototriggered Diels-Alder reaction. ${ }^{[132,155]}$ They employed a DielsAlder reaction to form a photoactive phencyclone precursor which releases $\mathrm{CO}$ and $\mathrm{H}_{2}$ upon UV irradiation. The photoproduct triphenyleneimide then undergoes a ring opening reaction with a peptide-based amine group to form a surfacegrafted peptide (Figure $8 \mathrm{~B}){ }^{[156]}$

\subsection{Responsive Materials and Self-Assembly}

Stimuli-responsive materials are defined by their ability to afford chemical or physical changes upon exposure to an external stimulus, including optical, electrical, thermal, mechanical, and chemical stimuli. ${ }^{[157]}$ Such materials are attracting everincreasing attention owing to their broad applications, such as in drug delivery, biosensors, and optical systems.

Photochromic materials are optically responsive materials with tunable colors owing to their incorporation of photochromic compounds such as spiropyrans which undergo a photoinduced isomerization from a colorless or slightly colored closed form to a highly colored open form. Recently, Tian and co-workers synthesized photochromic, spiropyranbased dendrimers using click chemistry. ${ }^{[158]}$ They employed both azide- and spiropyran-functionalized monomers, in combination with a multi-alkyne armed core, in a convergent dendrimer synthesis via the CuAAC reaction. These photochromic dendrimers showed better photochromic properties compared with simple spiropyran monomers and exhibited higher sensitivity towards ferric ion recognition. Genzer et al. embedded spiropyrans into silicone elastomer networks using poly(vinylmethylsiloxane) which was further modified with various functional thiols via thiol-ene addition. ${ }^{[159]}$ The color and modulus of these networks was tunable with UV and visible light exposure to effect the ring opening and closing of the spiropyran. Another interesting color switch example uses thermo-reversible Diels-Alder chemistry. ${ }^{[160]}$ They utilized a dithioester as a dienophile which is colored and observed alternating and fully reversible color changes when cycling 
(A)



(B)

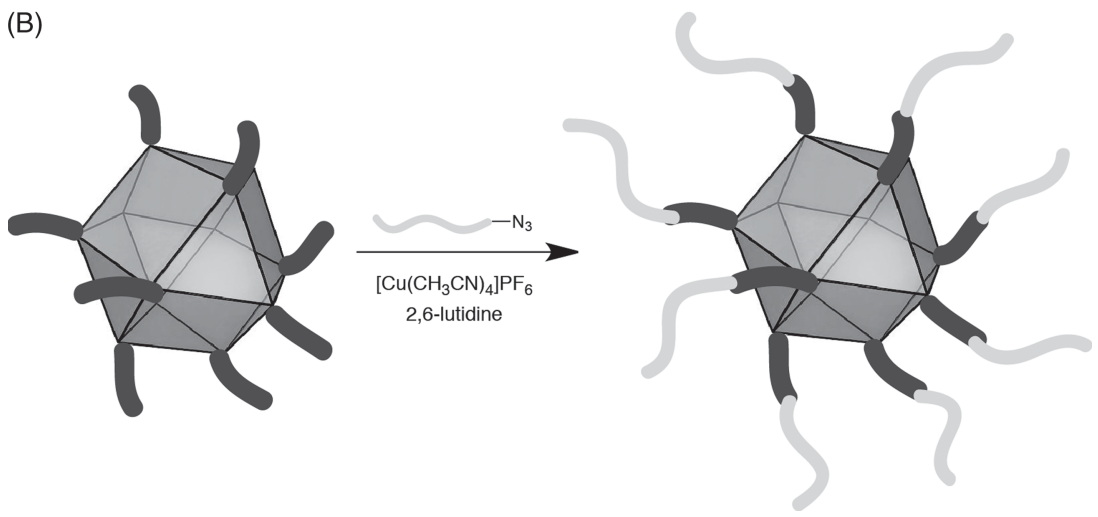

Figure 9. A) Ab azide functionalization with the NHS-PEC2000-Az linker and subsequent capsule functionalization. Adapted with permission. ${ }^{[163]}$ Copyright 2010, American Chemical Society. B) Nano cage modification using PEG azide. Adapted with permission. ${ }^{[161]}$

the temperature from $25{ }^{\circ} \mathrm{C}$ to $100{ }^{\circ} \mathrm{C}$, indicative of the rapid reversibility of this reaction.

One straightforward and important application of stimuliresponsive materials is in drug delivery. Recently, stimuliresponsive nanoparticles and nanocapusles have attracted significant attention because of their capacity to carry drug molecules and release them into the target cells. Several approaches have been developed to enhance the delivery efficiency of drug carriers by combining target molecules with suitable carriers such as polymer capsules. ${ }^{[161,162]}$ Caruso et al. developed an approach utilizing click chemistry to functionalize nano-sized polymer capsules with antibodies, enabling specific targeting of the antibody-conjugated capsules to cancer cells. ${ }^{[163]}$ The capsules, initially assembled using layer-by-layer deposition with an alkyne-functionalized poly( $N$-vinylpyrrolidone), were functionalized with PEG-azide-modified antibodies via the CuAAC reaction (Figure 9A). These antibody-functionalized polymer capsules were subsequently incubated with cancer cells and their targeting specificity were examined using fluorescence microscopy imaging. The authors found that $90 \%$ of cells were associated with modified polymer capsules, demonstrating high binding to cancer cells and the efficacy of their technique to modify polymer capsules using click chemistry for binding specificity. Recently, Zhou and coworkers synthesized porous, $\mathrm{Cu}(\mathrm{II})$-based coordination nanocages and similarly functionalized them using the CuAAC reaction with PEG-terminated azide (Figure 9B). ${ }^{[161]}$ This PEG modification made these nanocages into water-stable colloids which were shown to be a carrier of 5-fluorouracil, a powerful anticancer drug. Interestingly, as
$\mathrm{Cu}$ (II) is paramagnetic, these PEG-modified nanocages could play not only the role a of drug carrier, but could also can be used as a contrast agent in magnetic resonance imaging.

Guan et al. employed CuAAC ligation to synthesize extended poly(peptide)s from short, $\alpha, \omega$-functionalized peptide monomers incorporating azide and alkyne end groups. ${ }^{[164]}$ In this study, the authors protected an amide within the short peptide backbone with 2,4-dimethyloxybenzyl (DMB), an acid-labile group. This simple modification prevented aggregation of the poly(peptide) during synthesis; however, upon deprotection, the poly(peptide) self-assembled into well-defined $\beta$-sheets and formed hierarchical nanofibrils, as confirmed by transmission electron and atomic force microscopy. This approach was the first example of a synthetic polymer able to fold and self-assemble into $\beta$-sheets and demonstrated that click chemistry is a versatile and facile method to synthesize complex and hierarchical nanostructures (Figure 10A). Very recently, the Uljin group prepared a poly(oxazoline)-based copolymer with a phosphatase-sensitive block via the CuAAC reaction. ${ }^{[165]}$ Poly(oxazoline)s are well-known for exhibiting a lower critical solution temperature $\left(\mathrm{LCST} \sim 39^{\circ} \mathrm{C}\right.$ ), quite closed to physiological temperatures. Moreover, the incorporation of phosphatasesensitive groups in this polymer affords dual (both thermal and enzymatic) responsive behavior. Prior to the application of any stimulus, this polymer exhibited a weak, self-assembled structure. However, when the temperature was raised above the LCST, random aggregates formed. Upon enzymatic cleavage of the phosphates, the hydrophobicity of Fmoc-tyrosine moieties directed the material to self-assemble into micelles and, at temperatures above the LCST, the micellar structure collapsed. Also they demonstrated this thermal responsive process is reversible and after heating and cooling, the polymer went back to its initial state (Figure 10B).

\subsection{Nanomaterials Modification}

Over the past two decades, the fields of nanoscience and nanotechnology, wherein the manipulation of matter is performed at atomic or molecular scales to create novel and functional materials, have emerged. Nanoscale materials, such as quantum dots and nanotubes, represent promising candidates for future applications in optics, electronics, magnetics, mechanics and biomedicine owing to their unique structural, mechanical, magnetical and optical behavior. Unfortunately, the application development of nanomaterials is often impeded by their poor solubility, and consequently, a significant amount of research has focused on addressing this problem. One straightforward strategy to enhance the solubility of the nanomaterials 


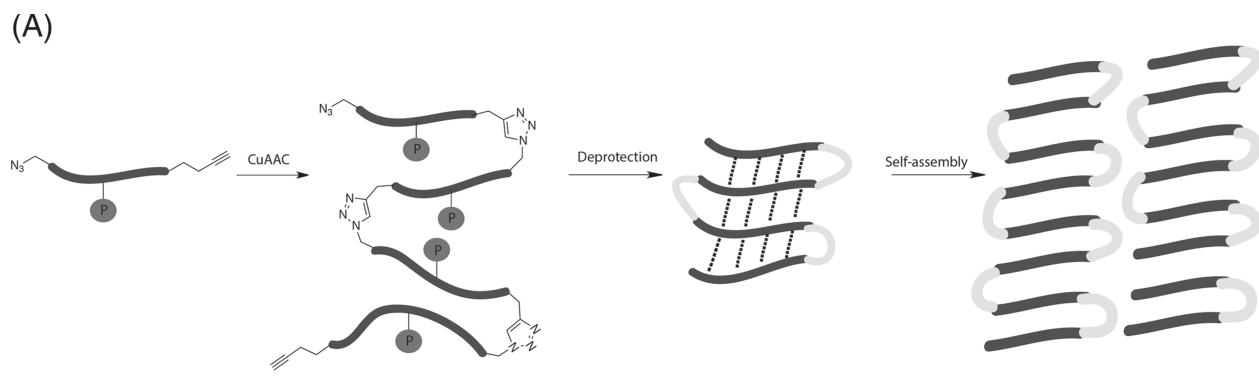

(B)

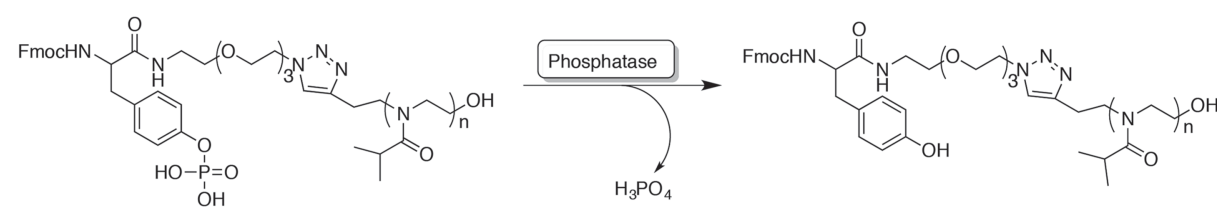



Figure 10. A) CuAAC-induced folding and self-assembly. Adapted with permission. ${ }^{[164]}$ B) Dual-stimuli responsive polymer self-assembly. Adapted with permission. ${ }^{165]}$ Copyright 2011, Royal Chemical Society.

is to covalently graft molecules to their surface. Owing to the common attributes of simplicity and modularity, and the ability to proceed to high conversion under mild reactions conditions, click chemistries have found significant utility in nanomaterial modification.

Carbon nanotubes are a class of nanomaterials that have attracted tremendous attention owing to their unique mechanical, electronic, and optical properties, and appropriate modification and functionalization of these carbon allotropes has become extremely important in applications. From the perspective of their chemical structural, carbon nanotubes are a large $\pi$-conjugated system which participates in cycloaddition and radical addition reactions; however, these reactions are often limited by incompatibility with the target molecules, and nanotube modification reactions typically require excess reagents to achieve a comparable yield. Thus, as it has proven necessary to employ more powerful chemistries to overcome these issues associated with carbon nanotube modification, the selectivity and efficiency of click chemistry makes it ideal for nanotube functionalization.

In 2005, Adronov et al. were the first to use the CuAAC reaction to functionalize single-wall nanotubes (SWNT). ${ }^{[166]}$ They used $p$-aminophenyl propargyl ether reacted with SWNTs in the presence of isoamyl nitrite to produce alkyne-functionalized SWNTs. Subsequently, azide-terminated polystyrene, prepared by sequential ATRP and nucleophilic substitution reactions, was affixed to the SWNTs via CuAAC (Figure 11A). Whereas both the unmodified and alkyne-modified nanotubes were insoluble in THF, chloroform and dichloromethane, the polystyrene-functionalized nanotubes exhibited excellent solubility in each of these solvents. Recently, a one-pot route to graft poly(carboxybetaine acrylamide) to SWNT was developed 
(A)

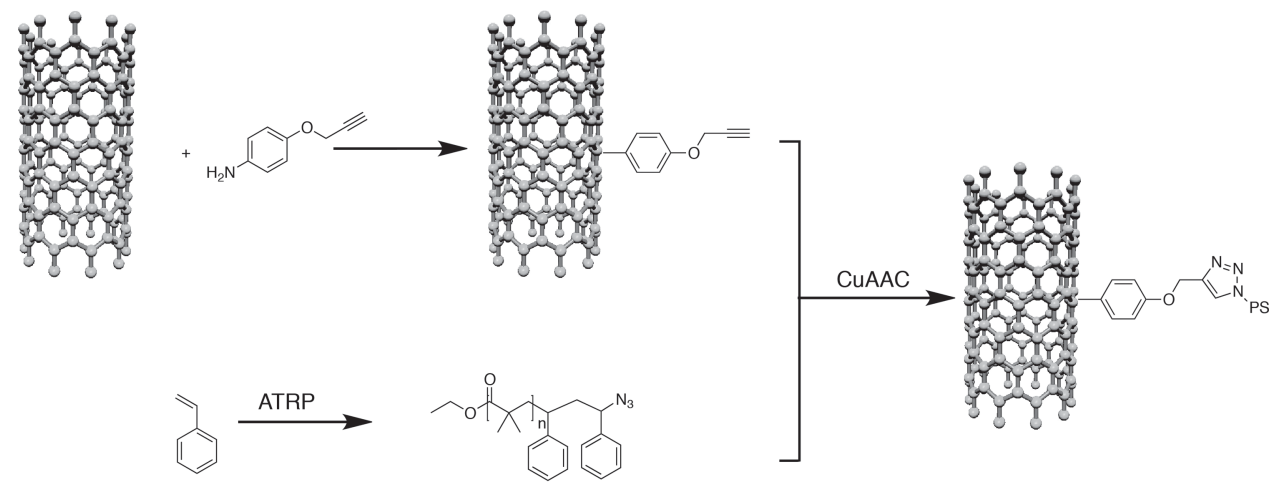

(B)

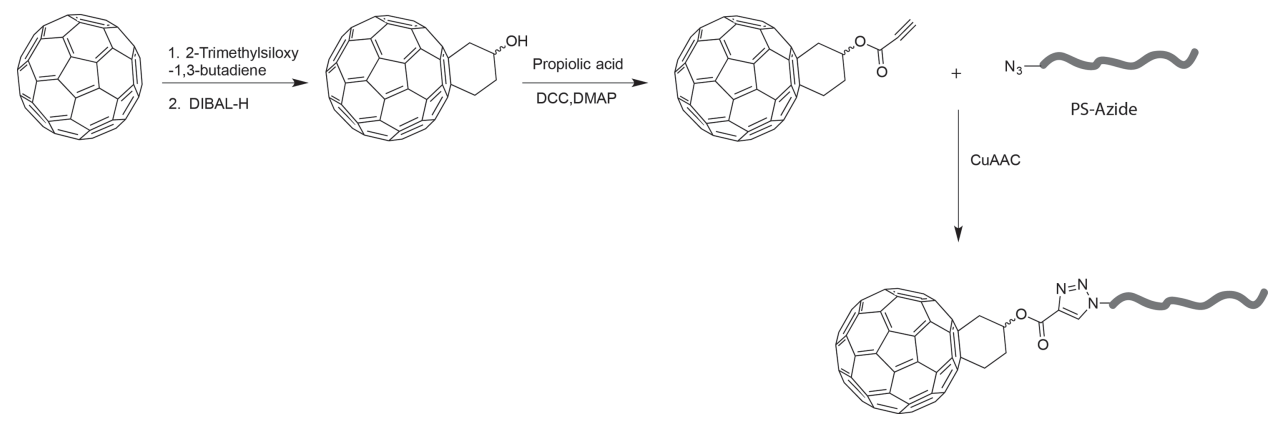

Figure 11. A) Synthesis of SWNT-polystyrene composite by reaction of 4-propargyloxyphenyl-SWNT and azide-polystyrene via CuAAC. Reproduced with permission. ${ }^{[166]}$ Copyright 2005, American Chemical Society. B) Preparation of polystyrene functionalized fullerene through fulleryne and azidepolystyrene via CuAAC. Reproduced with permission. ${ }^{[169]}$ Copyright 2008, American Chemical Society.

using Diels-Alder cycloaddition. ${ }^{[167]}$ The polymer functionalized SWNTs were further modified with single strand DNA that could hybridized to a fluorescently labeled complementary DNA strand. Click chemistry has since been used by an ever-increasing number of groups to effect nanotube modification, and a diverse range of pendant groups have been linked to nanotubes for different applications, such as using CuAAC to conjugate $\beta$-cyclodextrin to SWNTs for drug delivery. Fullerenes represent an interesting carbon nanostructure due to their unique structure and physicochemical behavior, ${ }^{[168]}$ and click chemistry has been repeatedly exploited to functionalize these molecules. In 2008, Cheng et al. used the CuAAC reaction to conjugate fullerene (C60) with various polymer strands. ${ }^{[169]}$ Firstly, fullerene was transformed to fulleryne using simple modification and esterification, then CuAAC was performed with azide modified polystyrene (Figure 11B).

Nanoparticles comprise another important class of nanomaterials and find utility in a broad range of applications, including photonics, catalysis, and biomedicine. Each of these applications originate from the diversity of modifications desired for nanoparticles. Consequently, there is a critical need for universal and effective methods for nanoparticle modification. The concept of click chemistry provides practical tools to solve this problem. A large research effort has been focused on using click chemistry to effect different kinds of nanoparticle modification. ${ }^{[170]}$ Magnetic nanoparticles based on iron oxides are attractive nanoparticles because of their application in biomedicine. Turro et al. reported using a ligand exchange method to graft alkyne-terminated ligands to metal oxide nanoparticles and subsequently utilizing the CuAAC reaction to graft various small molecules and polymers onto the nanoparticle surfaces (Figure 12A). ${ }^{[171]}$ These surface-functionalized nanoparticles were fully soluble in commonly used organic solvents without any aggregation. Another method for preparing azidemodified nanoparticles was developed by Reiser et al. ${ }^{[172]}$ Using a single-step approach, they fabricated nanoparticles composed of $\mathrm{Fe}_{3} \mathrm{O}_{4}$ encased in a $\mathrm{SiO}_{2}$ shell using 3-azidopropytriethoxysilane to yield azide-functionalized nanoparticles, and subsequently grafted $\mathrm{Cu}(\mathrm{II})$-azabis(oxazoline) to the magnetite@ silica nanoparticles. These modified nanoparticles were tested as catalysts for the asymmetric benzoylation of hydrobenzoin and were shown to exhibit both excellent catalytic activity and be readily removed by magnetic decantation (Figure 12B). Modification of catalytic nanoparticles has been performed using both small molecules and dendrimers. Astruc and coworkers firstly introduced dendrimer onto $\mathrm{Pd}(\mathrm{OAc})_{2}$ through click reaction and 1,2,3-triazole of groups in the dendrimer exhibits great capacity of nanoparticle stabilization and control nanoparticle size. ${ }^{[173]}$ They also found this clickable dendrimer functionalized nanoparticle showed enhanced catalytic activity compare with other 
(A)

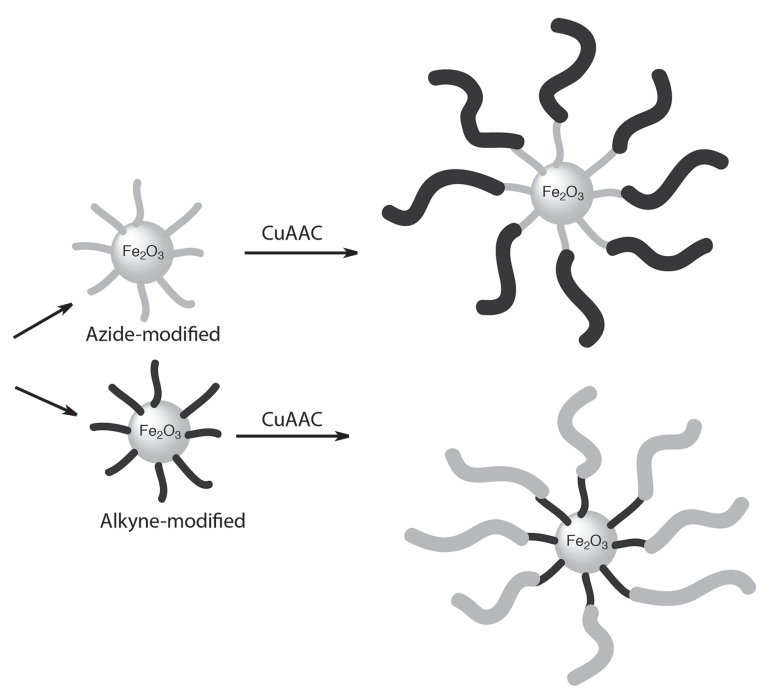

(B)

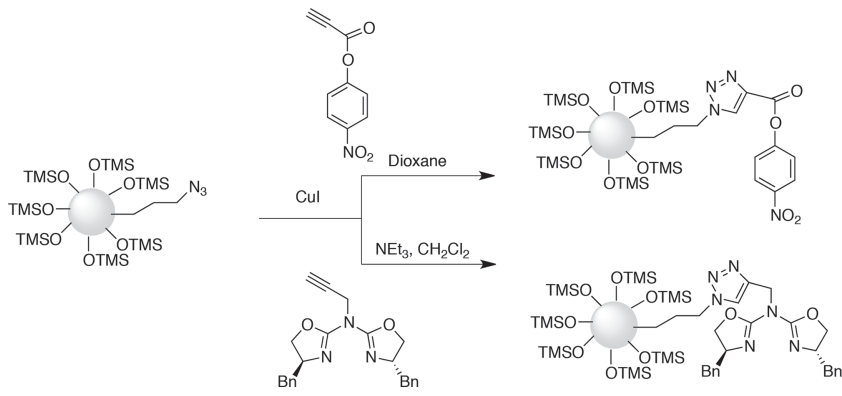

Figure 12. A) Functionalizing the surface of iron oxide nanoparticles using CuAAC. Adapted with permission. [171] Copyright 2006, American Chemical Society. B) Synthesis of azide-functionalized magnetite@silica nanoparticles a single-step protocol followed by TMS-endcapping of the surface silanol groups. Adapted with permission. ${ }^{[172]}$

dendrimer functionalized nanoparticle towards olefin hydrogenation. ${ }^{[173]}$ Furthermore, they also demonstrated this strategy successfully applied in Miyaura-Suzuki reaction. ${ }^{174]}$

\section{Conclusions and Outlook}

Although many click reactions have been developed and applied in materials science, the number of click reactions is still small compared with the enormity of the organic chemistry reaction library and with the need for this reaction paradigm, particularly in the materials area. Ultimately, for broader implementation in materials applications, three distinct directions must be pursued. First, the development of novel approaches to create clickable substrates, whether monomers, polymers, surfaces, or biological molecules will be critical. Given that the click concept seeks to include the entire process, approaches that yield prefunctionalized substrates directly will be of great advantage. Secondly, development of novel click reaction approaches remains a need, potentially including, as with the CuAAC reaction, the reconsideration and optimization of the catalyst and conditions to identify situations under which click-like performance is achieved. Finally, particularly for materials science, it will be critical that techniques are developed to control these click reactions. The demand for custom, on demand materials and material performance suggests that the development of improved methodologies for selectively starting and stopping these reactions will be necessary for their broad implementation in materials. Ultimately, with the development of click chemistry itself, new and more powerful functional materials will be designed, synthesized and fabricated for versatile and diverse applications. The potential of click chemistry within materials science is vast, and it is likely that click chemistry itself will serve as an excellent "catalyst" for continued development and expansion of materials science.

\section{Acknowledgements}

We would like to thank the National Science Foundation (DMR 1310528 and $\mathrm{CHE}$ 1214109) for providing financial support.

Received: August 13, 2013

Revised: October 25, 2013

Published online: January 21, 2014

[1] H. C. Kolb, M. G. Finn, K. B. Sharpless, Angew. Chem. Int. Ed. 2001, 40, 2004.

[2] C. Barner-Kowollik, F. E. Du Prez, P. Espeel, C. J. Hawker, T. Junkers, H. Schlaad, W. Van Camp, Angew. Chem. Int. Ed. 2011, 50, 60.

[3] V. V. Rostovtsev, L. G. Green, V. V. Fokin, K. B. Sharpless, Angew. Chem. Int. Ed. 2002, 41, 2596.

[4] C. W. Tornoe, C. Christensen, M. Meldal, J. Org. Chem. 2002, 67, 3057.

[5] C. E. Hoyle, A. B. Lowe, C. N. Bowman, Chem. Soc. Rev. 2010, 39, 1355.

[6] A. B. Lowe, Polym. Chem. 2010, 1, 17.

[7] P. Derboven, D. R. D'hooge, M. M. Stamenovic, P. Espeel, G. B. Marin, F. E. Du Prez, M. F. Reyniers, Macromolecules. 2013, 46, 1732.

[8] S. P. S. Koo, M. M. Stamenovic, R. A. Prasath, A. J. Inglis, F. E. Du Prez, C. Barner-Kowollik, W. Van Camp, T. Junkers, J. Polym. Sci. Pol. Chem. 2010, 48, 1699.

[9] R. Huisgen, Proc. Chem. Soc. London 1961, 357.

[10] F. Himo, T. Lovell, R. Hilgraf, V. V. Rostovtsev, L. Noodleman, K. B. Sharpless, V. V. Fokin, J. Am. Chem. Soc. 2005, 127, 210.

[11] J. E. Hein, V. V. Fokin, Chem. Soc. Rev. 2010, 39, 1302.

[12] M. Meldal, C. W. Tornoe, Chem. Rev. 2008, 108, 2952.

[13] P. Siemsen, R. C. Livingston, F. Diederich, Angew. Chem. Int. Ed. 2000, 39, 2633.

[14] Q. Wang, T. R. Chan, R. Hilgraf, V. V. Fokin, K. B. Sharpless, M. G. Finn, J. Am. Chem. Soc. 2003, 125, 3192.

[15] L. Zhang, X. Chen, P. Xue, H. H. Sun, I. D. Williams, K. B. Sharpless, V. V. Fokin, G. Jia, J. Am. Chem. Soc. 2005, 127 15998.

[16] B. C. Boren, S. Narayan, L. K. Rasmussen, L. Zhang, H. Zhao, Z. Lin, G. Jia, V. V. Fokin, J. Am. Chem. Soc. 2008, 130, 8923.

[17] S. Bakbak, P. J. Leech, B. E. Carson, S. Saxena, W. P. King, U. H. F. Bunz, Macromolecules 2006, 39, 6793.

[18] L. Peyrard, M. L. Dumartin, S. Chierici, S. Pinet, G. Jonusauskas, P. Meyrand, I. Gosse, J. Org. Chem. 2012, 77, 7023.

[19] A. E. Speers, G. C. Adam, B. F. Cravatt, J. Am. Chem. Soc. 2003, $125,4686$.

[20] J. F. Lutz, Angew. Chem. Int. Ed. 2008, 47, 2182. 
[21] N. J. Agard, J. A. Prescher, C. R. Bertozzi, J. Am. Chem. Soc. 2004, 126, 15046.

[22] C. G. Gordon, J. L. Mackey, J. C. Jewett, E. M. Sletten, K. N. Houk, C. R. Bertozzi, J. Am. Chem. Soc. 2012, 134, 9199.

[23] J. M. Baskin, J. A. Prescher, S. T. Laughlin, N. J. Agard, P. V. Chang, I. A. Miller, A. Lo, J. A. Codelli, C. R. Bertozzi, Proc. Natl. Acad. Sci. USA 2007, 104, 16793.

[24] X. Ning, J. Guo, M. A. Wolfert, G. J. Boons, Angew. Chem. Int. Ed. 2008, 47, 2253.

[25] A. A. Poloukhtine, N. E. Mbua, M. A. Wolfert, G. J. Boons, V. V. Popik, J. Am. Chem. Soc. 2009, 131, 15769

[26] J. C. Jewett, E. M. Sletten, C. R. Bertozzi, J. Am. Chem. Soc. 2010, 132,3688

[27] Z. M. Li, T. S. Seo, J. Y. Ju, Tetrahedron Lett. 2004, 45, 3143.

[28] C. R. Becer, R. Hoogenboom, U. S. Schubert, Angew. Chem. Int. Ed. 2009, 48, 4900.

[29] X. Deng, C. Friedmann, J. Lahann, Angew. Chem. Int. Ed. 2011, 50, 6522.

[30] T. G. Back, R. J. Bethell, M. Parvez, D. Wehrli, J. Org. Chem. 1998, 63, 7908.

[31] G. Labbe, Chem. Rev. 1969, 69, 345 .

[32] J. N. Brantley, K. M. Wiggins, C. W. Bielawski, Science 2011, 333, 1606.

[33] J. N. Brantley, S. S. Konda, D. E. Makarov, C. W. Bielawski, J. Am. Chem. Soc. 2012, 134, 9882.

[34] C. E. Hoyle, C. N. Bowman, Angew. Chem. Int. Ed. 2010, 49, 1540.

[35] A. Lowe, Abstracts Am. Chem. Soc. 2010, 240.

[36] C. E. Hoyle, T. Y. Lee, T. Roper, J. Polym. Sci. Pol. Chem. 2004, 42, 5301.

[37] C. N. Bowman, C. J. Kloxin, Aiche J. 2008, 54, 2775.

[38] L. J. Gou, B. Opheim, C. N. Coretsopoulos, A. B. Scranton, Chem. Eng. Commun. 2006, 193, 620

[39] T. M. Roper, T. Kwee, T. Y. Lee, C. A. Guymon, C. E. Hoyle, Polymer 2004, 45, 2921.

[40] M. A. Cole, K. C. Jankousky, C. N. Bowman, Polym. Chem. 2013, 4, 1167.

[41] B. J. Sparks, E. F. T. Hoff, L. P. Hayes, D. L. Patton, Chem. Mater. 2012, 24, 3633

[42] L. M. Campos, I. Meinel, R. G. Guino, M. Schierhorn, N. Gupta, G. D. Stucky, C. J. Hawker, Adv. Mater. 2008, 20, 3728.

[43] L. Chabanne, S. Pfirrmann, D. J. Lunn, I. Manners, Polym. Chem. 2013, 4, 2353.

[44] C. Boyer, A. Granville, T. P. Davis, V. Bulmus, J. Polym. Sci. Pol. Chem. 2009, 47, 3773.

[45] L. M. Campos, K. L. Killops, R. Sakai, J. M. J. Paulusse, D. Damiron, E. Drockenmuller, B. W. Messmore, C. J. Hawker, Macromolecules 2008, 41, 7063.

[46] A. Gress, A. Volkel, H. Schlaad, Macromolecules 2007, 40, 7928.

[47] C. Rissing, D. Y. Son, Organometallics 2009, 28, 3167.

[48] K. L. Killops, L. M. Campos, C. J. Hawker, J. Am. Chem. Soc. 2008, 130, 5062.

[49] Y. Geng, D. E. Discher, J. Justynska, H. Schlaad, Angew. Chem. Int. Ed. 2006, 45, 7578.

[50] D. Weinrich, P. C. Lin, P. Jonkheijm, U. T. T. Nguyen, H. Schroder, C. M. Niemeyer, K. Alexandrov, R. Goody, H. Waldmann, Angew. Chem. Int. Ed. 2010, 49, 1252

[51] L. Nurmi, J. Lindqvist, R. Randev, J. Syrett, D. M. Haddleton, Chem. Commun. 2009, 2727.

[52] B. D. Fairbanks, T. F. Scott, C. J. Kloxin, K. S. Anseth, C. N. Bowman, Macromolecules 2009, 42, 211.

[53] B. D. Fairbanks, E. A. Sims, K. S. Anseth, C. N. Bowman, Macromolecules 2010, 43, 4113

[54] R. Hoogenboom, Angew. Chem. Int. Ed. 2010, 49, 3415.

[55] A. B. Lowe, C. E. Hoyle, C. N. Bowman, J. Mater. Chem. 2010, 20, 4745.
[56] S. Chatani, D. P. Nair, C. N. Bowman, Polym. Chem. 2013, 4, 1048.

[57] J. W. Chan, C. E. Hoyle, A. B. Lowe, M. Bowman, Macromolecules 2010, 43, 6381

[58] W. X. Xi, C. Wang, C. J. Kloxin, C. N. Bowman, ACS Macro Lett. 2012, 1, 811

[59] B. M. Rosen, G. Lligadas, C. Hahn, V. Percec, J. Polym. Sci. Pol. Chem. 2009, 47, 3931.

[60] C. R. Becer, K. Babiuch, D. Pilz, S. Hornig, T. Heinze, M. Gottschaldt, U. S. Schubert, Macromolecules 2009, 42, 2387.

[61] E. Dyer, J. F. Glenn, J. Am. Chem. Soc. 1957, 79, 366.

[62] M. A. Tasdelen, Polym. Chem. 2011, 2, 2133.

[63] K. C. Nicolaou, S. A. Snyder, T. Montagnon, G. Vassilikogiannakis, Angew. Chem. Int. Ed. 2002, 41, 1668.

[64] B. J. Adzima, C. J. Kloxin, C. A. DeForest, K. S. Anseth, C. N. Bowman, Macromol. Rapid. Commun. 2012, 33, 2092.

[65] B. J. Adzima, H. A. Aguirre, C. J. Kloxin, T. F. Scott, C. N. Bowman, Macromolecules 2008, 41, 9112.

[66] X. X. Chen, M. A. Dam, K. Ono, A. Mal, H. B. Shen, S. R. Nutt, K. Sheran, F. Wudl, Science 2002, 295, 1698.

[67] O. Diels, K. Alder, Justus Liebigs Annalen Der Chemie 1928, 460, 98.

[68] Y. L. Liu, T. W. Chuo, Polym. Chem. 2013, 4, 2194.

[69] D. L. Boger, Chem. Rev. 1986, 86, 781.

[70] M. L. Blackman, M. Royzen, J. M. Fox, J. Am. Chem. Soc. 2008, 130,13518

[71] W. Song, Y. Wang, J. Qu, M. M. Madden, Q. Lin, Angew. Chem. Int. Ed. 2008, 47, 2832

[72] K. Gutsmiedl, C. T. Wirges, V. Ehmke, T. Carell, Org. Lett. 2009, 11, 2405

[73] C. Grundman, H. D. Frommeld, J. Org. Chem. 1966, 31, 157.

[74] S. Dey, T. L. Sheppard, Org. Lett. 2001, 3, 3983.

[75] A. Meyer, N. Spinelli, P. Dumy, J. J. Vasseur, F. Morvan, E. Defrancq, J. Org. Chem. 2010, 75, 3927.

[76] K. L. Heredia, Z. P. Tolstyka, H. D. Maynard, Macromolecules 2007, $40,4772$.

[77] H. Su, J. K. Zheng, Z. Wang, F. Lin, X. Y. Feng, X. H. Dong, M. L. Becker, S. Z. D. Cheng, W. B. Zhang, Y. W. Li, ACS Macro Lett. 2013, 2, 645.

[78] D. M. Beal, V. E. Albrow, G. Burslem, L. Hitchen, C. Fernandes, C. Lapthorn, L. R. Roberts, M. D. Selby, L. H. Jones, Org. Biomol. Chem. 2012, 10, 548.

[79] A. J. T. Dirks, S. S. van Berkel, N. S. Hatzakis, J. A. Opsteen, F. L. van Delft, J. J. L. M. Cornelissen, A. E. Rowan, J. C. M. van Hest, F. P. J. T. Rutjes, R. J. M. Nolte, Chem. Commun. 2005, 4172.

[80] H. Durmaz, A. Dag, G. Hizal, U. Tunca, J. Polym. Sci. Pol. Chem 2011, 49, 1195

[81] C. A. DeForest, B. D. Polizzotti, K. S. Anseth, Nat. Mater. 2009, 8, 659

[82] I. Singh, Z. Zarafshani, F. Heaney, J. F. Lutz, Polym. Chem. 2011, 2,372 .

[83] C. Wendeln, I. Singh, S. Rinnen, C. Schulz, H. F. Arlinghaus, G. A. Burley, B. J. Ravoo, Chem. Sci. 2012, 3, 2479.

[84] S. B. Rahane, R. M. Hensarling, B. J. Sparks, C. M. Stafford, D. L. Patton, J. Mater. Chem. 2012, 22, 932.

[85] J. W. Chan, C. E. Hoyle, A. B. Lowe, J. Am. Chem. Soc. 2009, 131, 5751.

[86] H. Durmaz, A. Dag, O. Altintas, T. Erdogan, G. Hizal, U. Tunca, Macromolecules 2007, 40, 191

[87] J. Shin, H. Matsushima, C. M. Comer, C. N. Bowman, C. E. Hoyle, Chem. Mater. 2010, 22, 2616.

[88] G. Clave, H. Volland, M. Flaender, D. Gasparutto, A. Romieu, P. Y. Renard, Org. Biomol. Chem. 2010, 8, 4329.

[89] L. Billiet, X. K. D. Hillewaere, F. E. Du Prez, Eur. Polym. J. 2012, 48, 2085.

[90] M. T. Gokmen, J. Brassinne, R. A. Prasath, F. E. Du Prez, Chem. Commun. 2011, 47, 4652. 
[91] M. Lo Conte, S. Staderini, A. Marra, M. Sanchez-Navarro, B. G. Davis, A. Dondoni, Chem. Commun. 2011, 47, 11086.

[92] P. Demay-Drouhard, E. Nehlig, J. Hardouin, L. Motte, E. Guenin, Chem. Eur. J. 2013, 19, 8388.

[93] S. Sinnwell, A. J. Inglis, M. H. Stenzel, C. Barner-Kowollik, Macromol. Rapid. Commun. 2008, 29, 1090.

[94] A. Vieyres, T. Lam, R. Gillet, G. Franc, A. Castonguay, A. Kakkar, Chem. Commun. 2010, 46, 1875.

[95] K. Kempe, R. Hoogenboom, M. Jaeger, U. S. Schubert, Macromolecules 2011, 44, 6424

[96] Y. G. Choi, H. Ishikawa, J. Velcicky, G. I. Elliott, M. M. Miller, D. L. Boger, Org. Lett. 2005, 7, 4539.

[97] A. A. Neves, H. Stockmann, Y. A. Wainman, J. C. H. Kuo, S. Fawcett, F. J. Leeper, K. M. Brindle, Bioconjugate. Chem. 2013, 24, 934.

[98] R. M. Broyer, E. Schopf, C. M. Kolodziej, Y. Chen, H. D. Maynard, Soft Matter 2011, 7, 9972.

[99] F. Lin, J. K. Zheng, J. Y. Yu, J. J. Zhou, M. L. Becker, Biomacromolecules 2013, 14, 2857.

[100] J. Shin, H. Matsushima, J. W. Chan, C. E. Hoyle, Macromolecules 2009, 42, 3294.

[101] F. Lin, J. Yu, W. Tang, J. Zheng, A. Defante, K. Guo, C. Wesdemiotis, M. L. Becker, Biomacromolecules 2013, 14, 3749.

[102] K. C. Koehler, K. S. Anseth, C. N. Bowman, Biomacromolecules 2013, 14, 538 .

[103] J. Schoch, M. Staudt, A. Samanta, M. Wiessler, A. Jaschke, Bioconjugate. Chem. 2012, 23, 1382.

[104] D. L. Alge, M. A. Azagarsamy, D. F. Donohue, K. S. Anseth, Biomacromolecules 2013, 14, 949.

[105] C. F. Hansell, R. K. O'reilly, ACS Macro Lett. 2012, 1, 896.

[106] A. Niederwieser, A. K. Spate, L. D. Nguyen, C. Jungst, W. Reutter, V. Wittmann, Angew. Chem. Int. Ed. 2013, 52, 4265.

[107] G. I. Elliott, J. R. Fuchs, B. S. J. Blagg, H. Ishikawa, H. C. Tao, Z. Q. Yuan, D. L. Boger, J. Am. Chem. Soc. 2006, 128, 10589.

[108] C. Rim, D. Y. Son, Tetrahedron Lett. 2009, 50, 4161.

[109] H. Yang, L. X. Lan, T. Tian, J. Cui, T. Zhu, D. Shen, G. Li, J. Mater. Chem. C 2013, 1, 6120.

[110] N. Gupta, B. F. Lin, L. M. Campos, M. D. Dimitriou, S. T. Hikita, N. D. Treat, M. V. Tirrell, D. O. Clegg, E. J. Kramer, C. J. Hawker, Nat. Chem. 2012, 4, 424.

[111] B. C. Sanders, F. Friscourt, P. A. Ledin, N. E. Mbua, S. Arumugam, J. Guo, T. J. Boltje, V. V. Popik, G. J. Boons, J. Am. Chem. Soc. 2011 133, 949.

[112] C. J. Hawker, A. W. Bosman, E. Harth, Chem. Rev. 2001, 101, 3661.

[113] T. Pintauer, K. Matyjaszewski, Chem. Soc. Rev. 2008, 37, 1087.

[114] K. Matyjaszewski, J. H. Xia, Chem. Rev. 2001, 101, 2921.

[115] G. Moad, E. Rizzardo, S. H. Thang, Polymer 2008, 49, 1079.

[116] J. Lahann, Click Chemistry for Biotechnology and Materials Science, WIley-VCH, Weinheim 2009.

[117] P. Theato, H.-A. Klok, Functional Polymers by Post-polymerization Modification: Concepts, Guidelines, and Applicatons, WIley-VCH, Weinheim 2012

[118] L. Nebhani, C. Barner-Kowollik, Adv. Mater. 2009, 21, 3442.

[119] B. S. Sumerlin, A. P. Vogt, Macromolecules. 2010, 43, 1.

[120] A. S. Goldmann, M. Glassner, A. J. Inglis, C. Barner-Kowollik, Macromol. Rapid. Commun. 2013, 34, 810.

[121] W. H. Binder, R. Sachsenhofer, Macromol. Rapid. Commun. 2008, 29, 952.

[122] B. S. Sumerlin, N. V. Tsarevsky, G. Louche, R. Y. Lee, K. Matyjaszewski, Macromolecules 2005, 38, 7540.

[123] N. Nenov, M. Koch, M. Klapper, K. Mullen, Polym. Bull. 2002, 47, 391.

[124] H. Ben Romdhane, M. R. Chaabouni, M. F. Grenier-Loustalot, F. Delolme, P. Mison, B. Sillion, Polymer 2000, 41, 1633.
[125] A. J. Inglis, T. Paulohrl, C. Barner-Kowollik, Macromolecules 2010, 43, 33.

[126] D. Quemener, T. P. Davis, C. Barner-Kowollik, M. H. Stenzel, Chem. Commun. 2006, 5051.

[127] E. M. Sletten, C. R. Bertozzi, Angew. Chem. Int. Ed. 2009, 48, 6974

[128] M. Fernandez-Suarez, H. Baruah, L. Martinez-Hernandez, K. T. Xie, J. M. Baskin, C. R. Bertozzi, A. Y. Ting, Nat. Biotechnol. 2007, 25, 1483.

[129] M. A. Tasdelen, Y. Yagci, Angew. Chem. Int. Ed. 2013, 52, 5930.

[130] A. A. Poloukhtine, N. E. Mbua, M. A. Wolfert, G. J. Boons, V. V. Popik, J. Am. Chem. Soc. 2009, 131, 15769.

[131] S. Arumugam, S. V. Orski, J. Locklin, V. V. Popik, J. Am. Chem. Soc. 2012, 134, 179.

[132] T. Pauloehrl, G. Delaittre, V. Winkler, A. Welle, M. Bruns, H. G. Borner, A. M. Greiner, M. Bastmeyer, C. Barner-Kowollik, Angew. Chem. Int. Ed. 2012, 51, 1071.

[133] T. Pauloehrl, G. Delaittre, M. Bruns, M. Meissler, H. G. Borner M. Bastmeyer, C. Barner-Kowollik, Angew. Chem. Int. Ed. 2012, 51, 9181.

[134] T. Gong, B. J. Adzima, C. N. Bowman, Chem. Commun. 2013, 49, 7950.

[135] B. J. Adzima, Y. Tao, C. J. Kloxin, C. A. DeForest, K. S. Anseth, C. N. Bowman, Nat. Chem. 2011, 3, 256.

[136] T. Gong, B. J. Adzima, N. H. Baker, C. N. Bowman, Adv. Mater. 2013, 25, 2024.

[137] M. A. Tasdelen, Y. Yagci, Tetrahedron Lett. 2010, 51, 6945.

[138] G. J. Chen, L. Tao, G. Mantovani, V. Ladmiral, D. P. Burt, J. V. Macpherson, D. M. Haddleton, Soft Matter 2007, 3, 732.

[139] Z. M. Wu, H. Liang, J. A. Lu, Macromolecules 2010, 43, 5699.

[140] K. Endo, New Frontiers Polym. Synthesis 2008, 217, 121.

[141] H. R. Kricheldorf, J. Polym. Sci. Pol. Chem. 2010, 48, 251.

[142] B. A. Laurent, S. M. Grayson, J. Am. Chem. Soc. 2006, 128, 4238.

[143] I. Nischang, O. Brueggemann, I. Teasdale, Angew. Chem. Int. Ed. 2011, 50, 4592.

[144] X. F. Yu, W. B. Zhang, K. Yue, X. P. Li, H. Liu, Y. Xin, C. L. Wang, C. Wesdemiotis, S. Z. D. Cheng, J. Am. Chem. Soc. 2012, 134, 7780

[145] J. W. Xu, X. Li, C. M. Cho, C. L. Toh, L. Shen, K. Y. Mya, X. H. Lu, C. B. He, J. Mater. Chem. 2009, 19, 4740.

[146] Y. W. Li, X. H. Dong, K. Guo, Z. Wang, Z. R. Chen, C. Wesdemiotis, R. P. Quirk, W. B. Zhang, S. Z. D. Cheng, ACS Macro Lett. 2012, 1, 834

[147] Y. W. Li, W. B. Zhang, I. F. Hsieh, G. L. Zhang, Y. Cao, X. P. Li C. Wesdemiotis, B. Lotz, H. M. Xiong, S. Z. D. Cheng, J. Am. Chem. Soc. 2011, 133, 10712.

[148] Z. Wang, Y. W. Li, X. H. Dong, X. F. Yu, K. Guo, H. Su, K. Yue, C. Wesdemiotis, S. Z. D. Cheng, W. B. Zhang, Chem. Sci. 2013, 4, 1345.

[149] P. Antoni, M. J. Robb, L. Campos, M. Montanez, A. Hult E. Malmstrom, M. Malkoch, C. J. Hawker, Macromolecules 2010, $43,6625$.

[150] C. A. DeForest, K. S. Anseth, Nat. Chem. 2011, 3, 925.

[151] S. El Habnouni, V. Darcos, X. Garric, J. P. Lavigne, B. Nottelet, J. Coudane, Adv. Funct. Mater. 2011, 21, 3321.

[152] B. Uszczynska, T. Ratajczak, E. Frydrych, H. Maciejewski, M. Figlerowicz, W. T. Markiewicz, M. K. Chmielewski, Lab Chip 2012, 12, 1151.

[153] N. Gupta, B. F. Lin, L. Campos, M. D. Dimitriou, S. T. Hikita, N. D. Treat, M. V. Tirrell, D. O. Clegg, E. J. Kramer, C. J. Hawker, Nat. Chem. 2010, 2, 138.

[154] S. V. Orski, A. A. Poloukhtine, S. Arumugam, L. D. Mao, V. V. Popik, J. Locklin, J. Am. Chem. Soc. 2010, 132, 11024.

[155] M. Glassner, K. K. Oehlenschlaeger, A. Welle, M. Bruns, C. Barner-Kowollik, Chem. Commun. 2013, 49, 633 
[156] T. Pauloehrl, A. Welle, K. K. Oehlenschlaeger, C. Barner-Kowollik, Chem. Sci. 2013, 4, 3503.

[157] M. A. C. Stuart, W. T. S. Huck, J. Genzer, M. Muller, C. Ober, M. Stamm, G. B. Sukhorukov, I. Szleifer, V. V. Tsukruk, M. Urban, F. Winnik, S. Zauscher, I. Luzinov, S. Minko, Nat. Mater. 2010, 9, 101.

[158] Q. Zhang, Z. J. Ning, Y. L. Yan, S. X. Qian, H. Tian, Macromol. Rapid. Commun. 2008, 29, 193.

[159] H. K. Yang, A. E. Ozcam, K. Efimenko, J. Genzer, Soft Matter 2011, 7, 3766.

[160] T. Paulohrl, A. J. Inglis, C. Barner-Kowollik, Adv. Mater. 2010, 22, 2788.

[161] D. Zhao, S. W. Tan, D. Q. Yuan, W. G. Lu, Y. H. Rezenom, H. L. Jiang, L. Q. Wang, H. C. Zhou, Adv. Mater. 2011, 23, 90.

[162] E. Lallana, A. Sousa-Herves, F. Fernandez-Trillo, R. Riguera, E. Fernandez-Megia, Pharmaceut. Res. 2012, $29,1$.

[163] M. M. J. Kamphuis, A. P. R. Johnston, G. K. Such, H. H. Dam, R. A. Evans, A. M. Scott, E. C. Nice, J. K. Heath, F. Caruso, J. Am. Chem. Soc. 2010, 132, 15881.

[164] T. B. Yu, J. Z. Bai, Z. B. Guan, Angew. Chem. Int. Ed. 2009, 48, 1097.
[165] P. F. Caponi, X. P. Qiu, F. Vilela, F. M. Winnik, R. V. Ulijn, Polym. Chem. 2011, 2, 306.

[166] H. M. Li, F. O. Cheng, A. M. Duft, A. Adronov, J. Am. Chem. Soc. 2005, 127, 14518.

[167] B. Yameen, C. Rodriguez-Emmenegger, I. Ahmed, C. M. Preuss, C. J. Durr, N. Zydziak, V. Trouillet, L. Fruk, C. Barner-Kowollik, Chem. Commun. 2013, 49, 6734.

[168] F. Giacalone, N. Martin, Chem. Rev. 2006, 106, 5136.

[169] W. B. Zhang, Y. Tu, R. Ranjan, R. M. Van Horn, S. Leng, J. Wang, M. J. Polce, C. Wesdemiotis, R. P. Quirk, G. R. Newkome, S. Z. D. Cheng, Macromolecules 2008, 41, 515.

[170] N. W. Li, W. H. Binder, J. Mater. Chem. 2011, 21, 16717.

[171] M. A. White, J. A. Johnson, J. T. Koberstein, N. J. Turro, J. Am. Chem. Soc. 2006, 128, 11356.

[172] A. Schatz, M. Hager, O. Reiser, Adv. Funct. Mater. 2009, 19, 2109.

[173] C. Ornelas, L. Salmon, J. R. Aranzaes, D. Astruc, Chem. Commun. 2007, 4946

[174] A. K. Diallo, C. Ornelas, L. Salmon, J. R. Aranzaes, D. Astruc, Angew. Chem. Int. Ed. 2007, 46, 8644. 